\title{
Effect of Mesoscale Eddies on Subtropical Mode Water Variability from the Kuroshio Extension System Study (KESS)
}

\author{
Bo Qiu, Shuiming Chen, And Peter Hacker \\ Department of Oceanography, University of Hawaii at Manoa, Honolulu, Hawaii
}

(Manuscript received 10 January 2006, in final form 4 August 2006)

\begin{abstract}
Forty-eight profiling floats have been deployed in the Kuroshio Extension (KE) region since May 2004 as part of the Kuroshio Extension System Study (KESS) project. By combining the float temperaturesalinity measurements with satellite altimetry data, this study investigates the role played by mesoscale eddies in controlling the property changes in North Pacific Subtropical Mode Water (STMW). Following a 3-yr period of low eddy activity in 2002-04, the KE showed a transition to a high eddy kinetic energy state in 2005. This transition is the result of delayed oceanic response to the 2002 shift in the basin-scale surface wind forcing in connection with the Pacific decadal oscillation. The high eddy kinetic energy state of the KE is characterized by successive shedding of strong cold-core rings into the recirculation gyre, resulting from the interaction of the KE jet with the Shatsky Rise or the preexisting cutoff rings. By transporting northernorigin, high-potential-vorticity (PV) KE water into the recirculation gyre, the enhanced eddy activity affects STMW in two ways: first, it hinders the formation of deep winter mixed layer (hence the source for STMW) by modifying the upper-ocean stratification and, second, it provides a direct high-PV source to mix with the surrounding low-PV STMW. The eddies' influence upon STMW is observed to be both significant in magnitude and efficient in time. Relative to 2004, the PV signal in the core of STMW was reduced by one-half in 2005, and this weakening of STMW's intensity occurred within a period of less than 7 months. This result supports recent findings by the authors based on historical temperature data that the variability in STMW formation depends more sensitively on the dynamic state of the KE than on the overlying atmospheric conditions.
\end{abstract}

\section{Introduction}

A universal feature of the subtropical gyre circulation in the world oceans is the presence of a thick layer of weak temperature gradient on the equatorward side of the gyre's western boundary current extension [see Hanawa and Talley (2001) for a comprehensive review]. In the North Pacific Ocean, this mode water is commonly referred to as the Subtropical Mode Water (STMW; Masuzawa 1969, 1972). Like mode waters in other western subtropical basins, STMW exists in between the seasonal and permanent thermoclines, and is formed because of the regional, wintertime convective cooling (Bingham 1992; Suga and Hanawa 1995a; Suga et al. 2004).

Because STMW serves as a sequestered heat reser-

Corresponding author address: Dr. Bo Qiu, Department of Oceanography, University of Hawaii at Manoa, 1000 Pope Road, Honolulu, HI 96822.

E-mail: bo@soest.hawaii.edu voir that can potentially modulate regional and remote surface/subsurface temperature signals (Vivier et al. 2002; Qiu 2002; Deser et al. 2003; Kelly 2004), a number of studies in recent years have investigated the longterm changes in the STMW properties. For example, Bingham et al. (1992) found that STMW was thicker and more uniform in temperature during 1938-42 than during 1978-82. They attributed this difference to the stronger wintertime cooling during the 1938-42 pentad. Based on repeat hydrographic surveys along the $137^{\circ} \mathrm{E}$ meridian south of Japan, Suga and Hanawa (1995b) found a good correlation between the observed STMW properties and the surface pressure difference between Nemuro, Japan, and Irkutsk, Russia, which serves as an index for the strength of the wintertime East Asian Monsoon. The fact that a more intense monsoon results in the formation of a deeper mixed layer and thicker and colder STMW has also been stressed in other recent studies by Yasuda and Hanawa (1999), Taneda et al. (2000), and Hanawa and Kamada (2001).

Because STMW forms adjacent to the Kuroshio Ex-

DOI: $10.1175 / J P O 3097.1$

(C) 2007 American Meteorological Society 
tension (KE) where enhanced mesoscale eddy variability is detected, two recent studies have explored the roles played by the mesoscale eddies in the formation of STMW. Based on Argo profiling float data acquired in 2001, Uehara et al. (2003) observed that anticyclonic mesoscale eddies tend to trap more intense STMW than cyclonic mesoscale eddies. By analyzing historical CTD/XBT and profiling float data, Qiu and Chen (2006) found that STMW formation depends sensitively on the dynamic state of the KE. The formation rate is reduced when the $\mathrm{KE}$ path is in a variable state in which high regional eddy variability infuses high potential vorticity KE water into the recirculation gyre, increasing the upper-ocean stratification and hindering the development of a deep winter mixed layer. A stable KE path with suppressed eddy variability, on the other hand, favors the maintenance of a weak stratification in the recirculation gyre, leading to a deep winter mixed layer and formation of a thick STMW layer.

One important issue that was not addressed in the aforementioned studies is the time scale on which mesoscale eddies are able to alter the upper-ocean stratification inside the recirculation gyre. The historical temperature dataset simply does not have the needed spatial and temporal coverage to adequately address this question. Dynamically, this is an important issue because STMW is renewed convectively on an annual basis. If the dynamic influence of the mesoscale eddies acts on the slower interannual time scale, one may expect a stronger control on the STMW variability by the wintertime atmospheric condition, rather than the oceanic eddy-induced preconditioning effect. To fully understand the oceanic versus atmospheric control on STMW, an in-depth examination into how mesoscale eddies modify the upper-ocean stratification in the recirculation gyre is called for.

In 2003, a collaborative research program named Kuroshio Extension System Study (KESS) was initiated. One of the objectives of KESS is to clarify the processes that govern the temporal variability of STMW and the KE mesoscale eddy field. (Complete scientific objectives of KESS can be found online at http:// www.po.gso.uri.edu/dynamics/KESS.) Twenty Apex proiling floats were deployed in the KE recirculation gyre in May-June 2004, and another set of 28 floats were deployed in May-June 2005. With a repeat cycle of 5 days, an unprecedented amount of high-verticalresolution temperature-salinity $(T-S)$ profiles has been collected from the KE in the past two years. By combining the profiling $T-S$ data with the mesoscale-resolving sea surface height ( $\mathrm{SSH}$ ) data from multiple satellite altimetry missions, we seek to quantitatively evaluate the effect of mesoscale eddies on the STMW variability.
It is worth mentioning that the KE system underwent a transition in late 2004 from a relatively stable state to an unstable state in which the KE path became highly variable and the regional eddy kinetic energy (EKE) level was nearly doubled. As will be described in section 3, this transition in the KE's dynamic state is connected to the decadal changes in the basin-scale surface wind field of the North Pacific Ocean. The occurrence of this transition is fortuitous as it provides us with an opportunity to contrast the STMW signals in the two different dynamic states of the KE, and to quantify the eddy-induced STMW transformation using the 2-yr, densely sampled KESS measurement data.

\section{The 2005 KESS survey}

Following the first cruise in April-June of 2004, a second KESS cruise was conducted on board the R/V Revelle from 25 May to 17 July 2005 [see Qiu et al. (2006) for details of the first KESS cruise]. During this second-year cruise, the 46 current and pressure recording inverted echo sounders (CPIES), the seven moored profiler (MP) moorings, and the Kuroshio Extension Observatory (KEO) surface mooring that were deployed in 2004 were either recovered or refurbished. A new set of 46 CPIES, eight MPs, and an enhanced KEO surface mooring were deployed. Out of the 20 Apex profiling floats deployed during the first KESS cruise, 19 are still functioning well and are measuring the $T-S$ field as originally planned. Their positions in early June 2005 are denoted in Fig. 1 by blue squares. On the second KESS cruise, a new set of 28 Apex profiling floats were deployed (green circles in Fig. 1).

Like their first-year counterparts, the new Apex floats conduct $T-S$ measurements every 5 days as they arise from the $1500-\mathrm{m}$ parking depth. The measurements have a vertical resolution of $5 \mathrm{~m}$ in the surface $100-\mathrm{m}$ layer, $10 \mathrm{~m}$ in the $100-400-\mathrm{m}$ layer, $30 \mathrm{~m}$ in the 400-1000-m layer, and $100 \mathrm{~m}$ in the 1000-1500-m layer. Detailed information regarding the float data and the preliminary analysis results are available online at http://www.soest.hawaii.edu/snol. To complement the KESS profiling float data, we also include in this study the $T-S$ data from the profiling floats that are in the domain and period of our interest from the Japanese Argo program (Oka and Suga 2003). For all the profiling data, a delayed-mode quality control is conducted following a procedure similar to that proposed by Wong et al. (2003). Specifically, the measured $T-S$ data are compared with the $1^{\circ} \times 1^{\circ}$ World Ocean Atlas 2001 climatological data (Conkright et al. 2002). The data are excluded if they fall outside the two-standarddeviation envelopes of the local, climatological $T-S$ curve. 


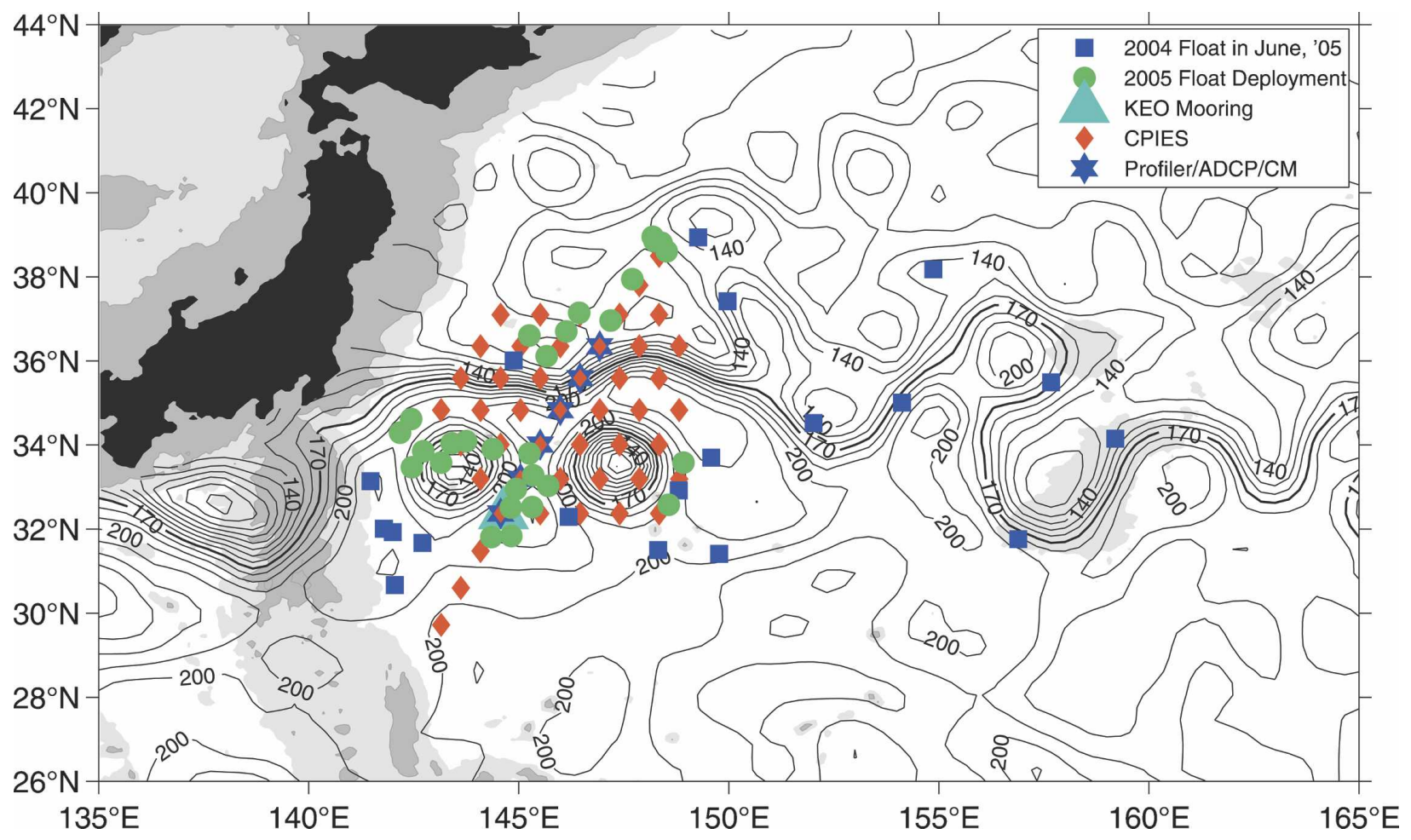

FIG. 1. KESS observing array deployed in May-June 2005. Contours denote the June 2005 SSH field from satellite altimetric data (cm) and Teague et al. (1990). Light and dark gray shadings denote the 2000- and 4000-m depth contours, respectively. Major bathymetric features in the region include the Izu Ridge along $140^{\circ} \mathrm{E}$ and the Shatsky Rise around $159^{\circ} \mathrm{E}$.

To capture better the time-varying KE jet, the recirculation gyre, and the mesoscale eddy field, we combine in this study the float $T-S$ data with satellite altimetry data. For this purpose, we use the global SSH anomaly dataset compiled by the Collecte, Localisation, Satellites (CLS) Space Oceanographic Division of Toulouse, France. The dataset merges the Ocean Topography Experiment (TOPEX)/Poseidon, Jason-1, and European Remote Sensing Satellite (ERS)-1/2 along-track SSH measurements and has improved capability of detecting mesoscale SSH signals (Le Traon and Dibarboure 1999; Ducet et al. 2000). The CLS SSH anomaly dataset has a 7-day temporal resolution and a $1 / 3^{\circ} \times 1 / 3^{\circ}$ spatial resolution. For the mean SSH field, we adopt the surface dynamic height (0/1000 dbar) climatological values compiled by Teague et al. (1990). Given the mean SSH field, the absolute SSH field is simply the sum of the mean and anomalous SSH data. For brevity, the absolute SSH field will be referred to as the SSH field throughout this study.

\section{KE dynamic state in 2004 versus 2005}

Following the launch of the TOPEX/Poseidon altimeter satellite in 1992, our ability to observe the time- varying surface ocean circulation has improved significantly. During the 14 yr since 1992, the KE jet and its southern recirculation gyre have been observed to oscillate between a stable state in the which the KE jet had a relatively stable path and a well-defined southern recirculation gyre, and an unstable state in which the KE path is highly variable and the regional EKE level is elevated (Qiu and Chen 2005). The transition from a stable to an unstable state occurred in mid 1995 and the reverse transition from an unstable to a stable state occurred at the beginning of 2001. While the KESS observations have been under way in the past two years the KE system experienced another transition from a stable to an unstable state. In this section, we first provide a detailed description of this transition based on the satellite altimetry data. The cause for this recent transition is then discussed in relation to the Pacific decadal oscillations (PDOs; Mantua et al. 1997).

Figure 2 shows sequential SSH maps from April 2004 to March 2005, with each map giving a snapshot of the SSH field in the first week of the month. Throughout 2004, the KE jet shows the classical pattern of two quasi-stationary meanders (e.g., Mizuno and White 1983) and is accompanied by a well-defined southern recirculation gyre (identifiable in Fig. 2 by areas where 

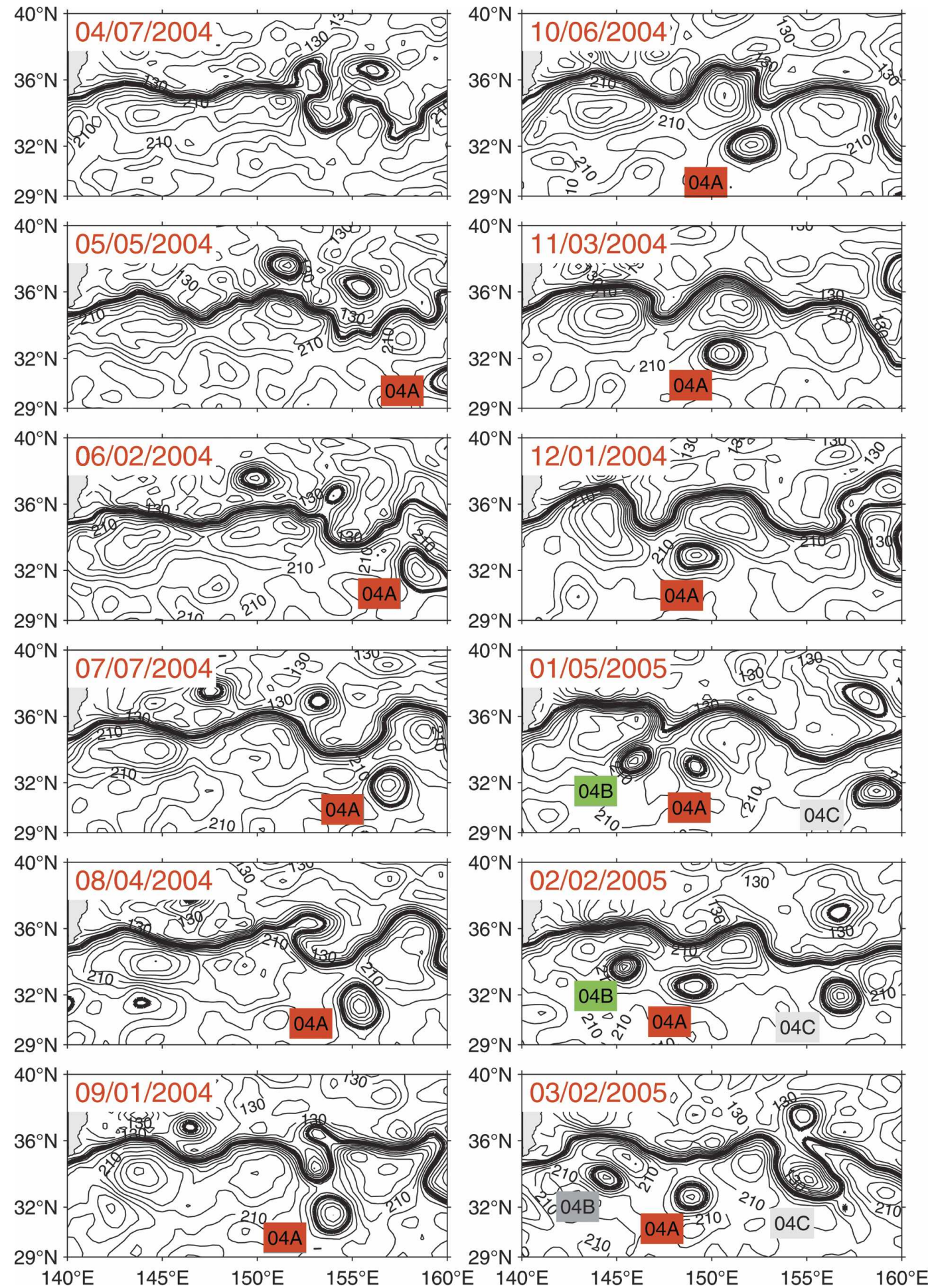

FIG. 2. Snapshots of the SSH field in April 2004-March 2005. Contour intervals are $10 \mathrm{~cm}$, with the thick black lines denoting the $170 \mathrm{~cm}$ contours. Cold-core rings are labeled sequentially according to their cutoff timings. 
the $\mathrm{SSH}$ values exceed $220 \mathrm{~cm}$ ). During this period, the $\mathrm{KE}$ jet and the recirculation gyre were relatively stable and, as noted above, this stable pattern had persisted through the preceding $3 \mathrm{yr}$ after the KE system transitioned from an unstable to a stable state at the beginning of 2001. Notice that in May-June 2004, an intense cold-core ring detached from the main KE jet near $158^{\circ} \mathrm{E}$. With seamounts extending to as shallow as 2500 $\mathrm{m}$, the Shatsky Rise near $158^{\circ} \mathrm{E}$ (see Fig. 1 for the regional bathymetry) has been noted by many previous studies as a preferential site for generating mesoscale eddies as a result of the interaction of the deep KE jet with the bottom topography (Hurlburt et al. 1996; Ebuchi and Hanawa 2001). Being the first intense coldcore ring cut off from the KE jet in 2004, the ring will be referred to as CCR-04A in this study.

Following its formation, CCR-04A propagated westward at a relatively constant speed of $5.7 \mathrm{~cm} \mathrm{~s}^{-1}$. This steady westward propagation was, however, interrupted in early December when CCR-04A approached the trough of the quasi-stationary meander of the KE jet near $147^{\circ} \mathrm{E}$. Interaction between the trough and the approaching eddy forced CCR-04A to stall and the meandering trough to steepen. The latter detached from the KE jet in mid-December and became the second cold-core ring in 2004, CCR-04B (see the SSH map of 5 January 2005 in Fig. 2; further discussion of the CCR04B detachment will be given in section 4).

After its detachment, CCR-04B drifted westward from January to April in 2005 (Fig. 3). In the subsequent 4 months from May to August, however, it became largely stationary upon reaching $144^{\circ} \mathrm{E}$ near the center of the recirculation gyre. In late August, CCR04B started to interact with the inflow KE jet southeast of Japan and the ring was subsequently absorbed by the $\mathrm{KE}$ jet in early September. After inducing the formation of CCR-04B, CCR-04A, on the other hand, continued to interact with the KE jet near $147^{\circ} \mathrm{E}$. This interaction was particularly vigorous in April-June 2005 when CCR-04A became temporally absorbed and later on redetached from the KE jet. CCR-04A was eventually absorbed by the KE jet near $147^{\circ} \mathrm{E}$ in $\mathrm{Au}-$ gust 2005.

In mid-December 2004, a third cold-core ring, CCR04C, can be seen in Fig. 2 to have formed near the Shatsky Rise. After separating from the KE jet, CCR04C started to drift westward in a manner similar to CCR-04A. Unlike its predecessor, however, CCR-04C was absorbed by the KE jet in March 2005 when it approached the trough of the second KE quasistationary meander near $155^{\circ} \mathrm{E}$. Notice that although the three cold-core rings generated in 2004 had all disappeared by September 2005, Fig. 3 shows that by this time a new cold-core ring, CCR-05A, had formed near the Shatsky Rise. Through the beginning of March 2006, the westward-drifting CCR-05A behaved very similarly to CCR-04A.

As a result of the enhanced mesoscale eddy formation and the eddies' interaction with the KE jet, the KE path in 2005 can be seen in Fig. 3 to be more variable than that in 2004 (cf. Fig. 2). In connection to this change in the stability of the KE path, the southern recirculation gyre becomes less well-defined in 2005, and the regional EKE level, calculated geostrophically from the SSH data in the KE region of $32^{\circ}-38^{\circ} \mathrm{N}$ and $141^{\circ}-153^{\circ} \mathrm{E}$, nearly doubles in 2005 over that in 2004 (Fig. 4a; note that the time series here is plotted as the deviation from the regional mean EKE value).

It is helpful here to place the 2004/05 transition of the KE system from a stable to an unstable state in a broader, spatial, and temporal context. As indicated in Fig. 4a, the low-EKE state of 2004 has continued from 2002, and a similar low-EKE state persisted from November 1992 (the beginning of the TOPEX/Poseidon satellite altimetry mission) to mid 1996. In contrast, the high-EKE state of 2005 prevailed over the period from mid-1996 to the end of 2001. This decadal modulation in the EKE field is controlled by the dynamic state of the KE system, which is typified by the strength of the recirculation gyre. Figure 4b shows the SSH anomalies along the recirculation gyre band of $32^{\circ}-34^{\circ} \mathrm{N}$ across the North Pacific basin as a function of time and longitude. A positive (negative) anomaly over the western region of $141^{\circ}-160^{\circ} \mathrm{E}$ indicates a strengthened (weakened) recirculation gyre. A negative correlation between the strength of the recirculation gyre and the level of EKE in the upstream KE region over the decadal time scale is qualitatively identifiable in Figs. 4a and 4b [see Qiu and Chen (2005) for a more in-depth analysis].

It is important to notice from Fig. $4 \mathrm{~b}$ that the decadal SSH modulations associated with the recirculation gyre originate in the central North Pacific around $160^{\circ} \mathrm{W}$. This is the region where the surface wind forcing has the highest decadal variance in the North Pacific Ocean and is the action center of the PDO-related wind anomalies (see, e.g., Fig. 2 in Qiu 2003). Figure 4c shows the PDO index for the period of our interest; here a positive (negative) value represents a positive (negative) wind stress curl anomaly over the central North Pacific Ocean and it works to lower (raise) the local SSH through Ekman flux divergence (convergence). When these wind-induced, negative (positive) SSH anomalies propagate westward into the KE region, they tend to switch the KE system into an unstable (stable) dynamic state (Qiu and Chen 2005). In- 

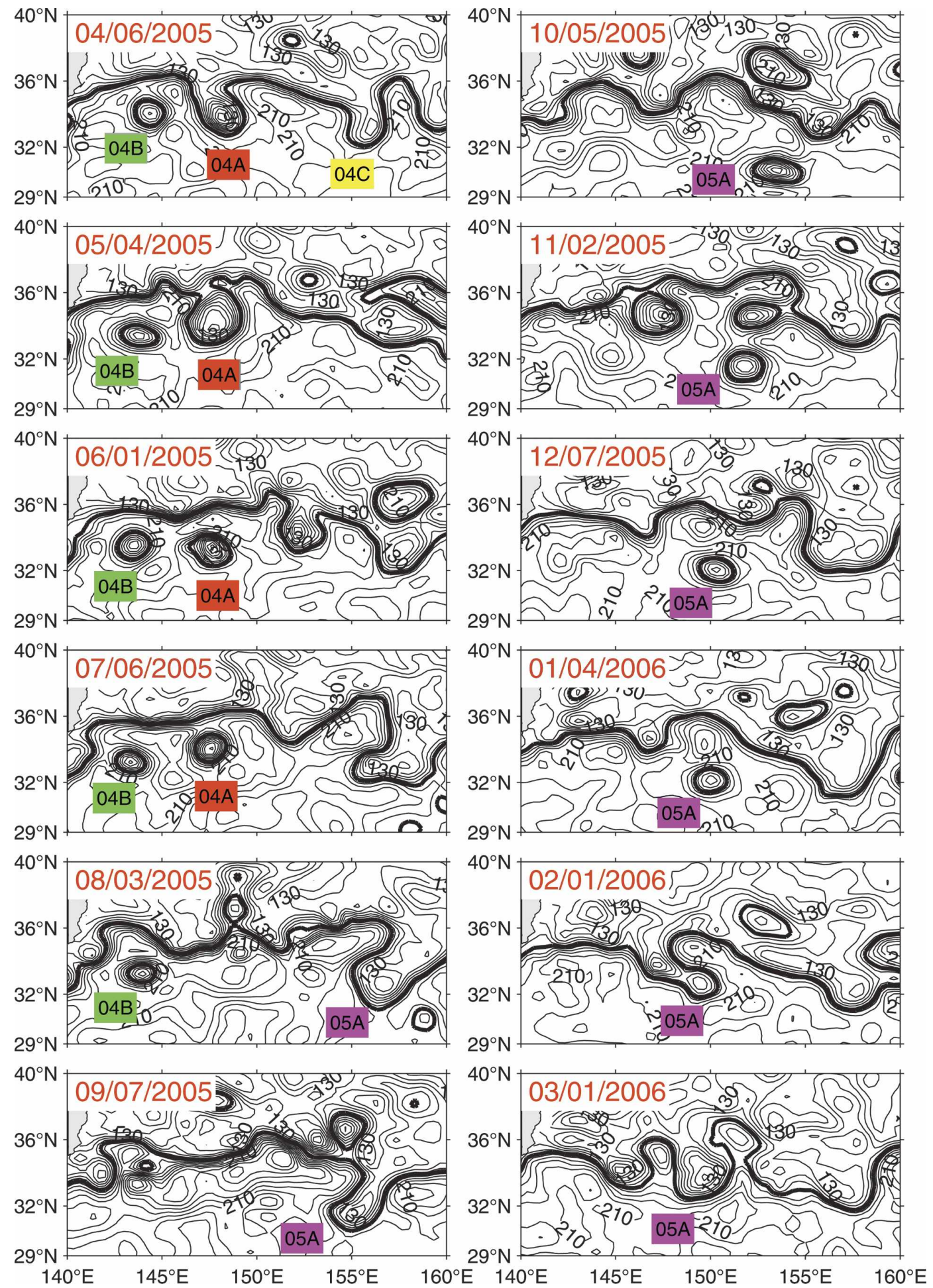

Fig. 3. Same as for Fig. 2, but for April 2005-March 2006.

deed, there exists a high correlation between the EKE time series in the upstream KE region and the PDO index when the latter leads the EKE time series by $4 \mathrm{yr}$ (cf. Figs. 4a and 4c; see Fig. 5).
In short, the 2004/05 transition of the KE dynamic state is the delayed oceanic response to the PDO transition from a negative to a positive phase that occurred in mid-2002. The PDO index and the SSH data in the 

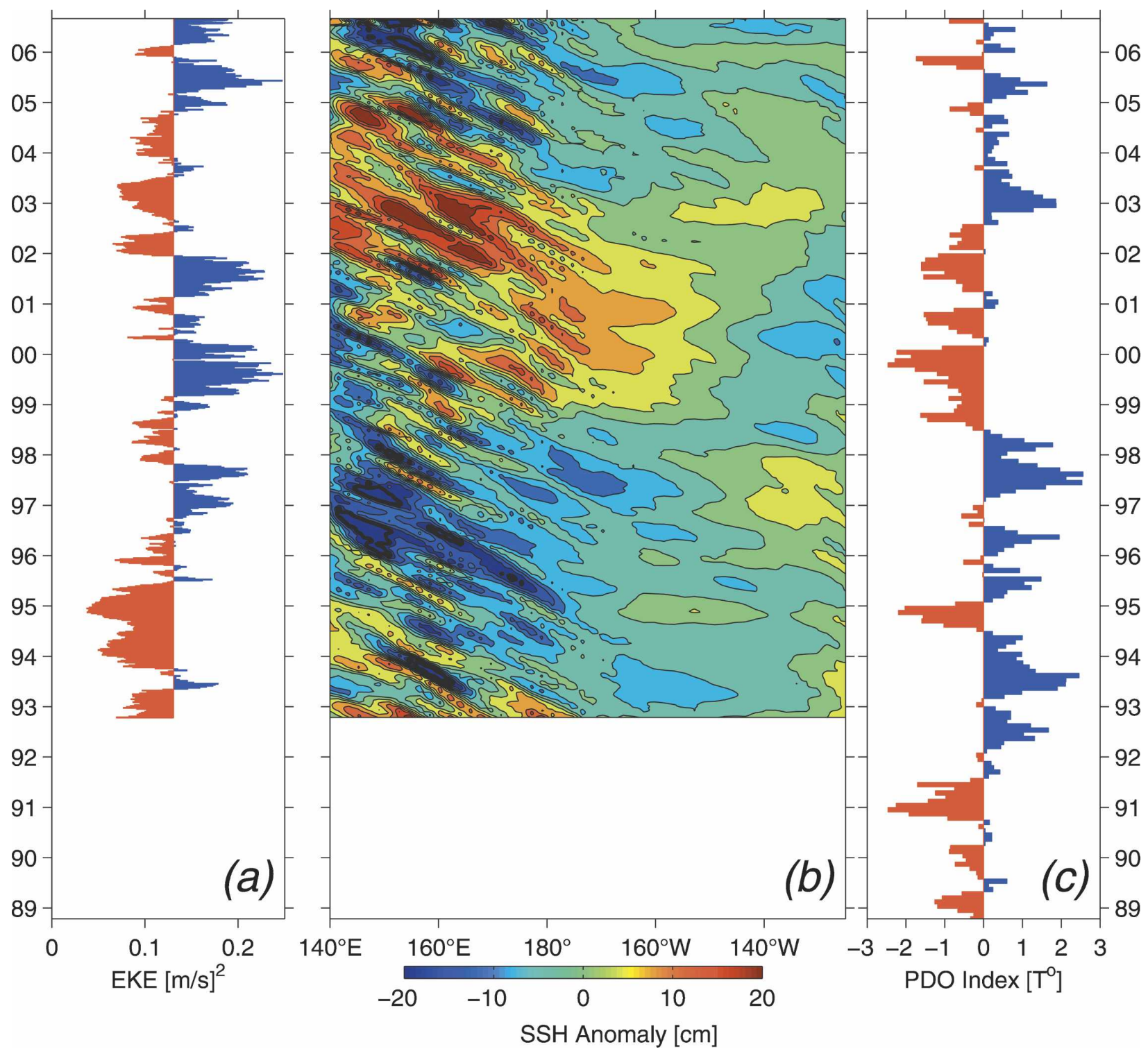

FIG. 4. (a) Time series of EKE in the upstream KE region of $141^{\circ}-153^{\circ} \mathrm{E}$ and $32^{\circ}-38^{\circ} \mathrm{N}$. Here, EKE is calculated using the weekly SSH anomaly data by assuming geostrophy. For comparison with the PDO index, the time series is plotted as the deviation from the regional mean EKE value. (b) Sea surface height anomalies along the zonal band of $32^{\circ}-34^{\circ} \mathrm{N}$. The KE recirculation gyre occupies the western segment of $140^{\circ}-160^{\circ} \mathrm{E}$. (c) $\mathrm{PDO}$ index from http://jisao.washington.edu/pdo/PDO.latest.

central North Pacific suggest that the unstable, highEKE state of the KE is likely to persist through the coming $2-3$ yr.

\section{Impact of enhanced eddy variability}

Given the enhanced eddy variability in 2005 , it is natural to ask to what extent this change in the dynamic state of the KE affects the regional watermass properties. To address this question, we plot in Fig. 6 the monthly distributions of potential vorticity (PV) on the
$25.375 \sigma_{\theta}$ density surface based on the available $T-S$ profiles in the KESS period. Here, PV is defined by (Talley 1988)

$$
Q \equiv-\frac{f}{\rho} \frac{\partial \sigma_{\theta}}{\partial z},
$$

where $f$ is the Coriolis parameter and $\rho$ is the water density. The $25.375 \sigma_{\theta}$ density surface is chosen to represent the STMW core layer (Hanawa and Talley 2001); a lower (higher) PV value on this density surface indicates the presence of a stronger (weaker) pycnostad 


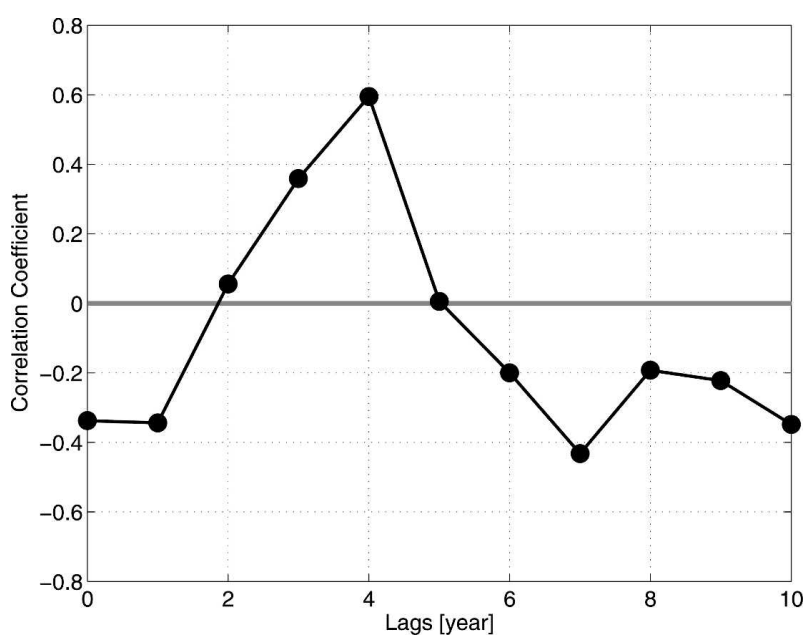

FIG. 5. Lagged correlation between the yearly time series of EKE in the upstream KE region (Fig. 4a) and that of the PDO index (Fig. 4c). Positive lags here indicate the lead of the PDO index over the EKE signals.

of STMW. Inside the KE recirculation gyre, Fig. 6 reveals clearly that the STMW pycnostad was better developed in 2004 than in 2005: the PV value in the STMW core layer was generally below $0.5 \times 10^{-10} \mathrm{~m}^{-1}$ $\mathrm{s}^{-1}$ in 2004 when the mesoscale eddy activity was low, and it increased to above $1.0 \times 10^{-10} \mathrm{~m}^{-1} \mathrm{~s}^{-1}$ after the regional EKE level was elevated in 2005.

Notice that the increase in PV is not only confined to inside the cold-core rings. A comparison, for example, between the two June (or July) maps in Fig. 6 reveals that the PV values outside of the cold-core rings are also higher in 2005 than in 2004. To have a closer look at the evolution of the water mass properties inside the KE recirculation gyre, we plot in Figs. $7 \mathrm{a}$ and $7 \mathrm{~b}$ the time series of $T(z, t)$ and $S(z, t)$ constructed by combining the available $T-S$ profiles within the recirculation gyre. Here, a profile is regarded as within the recirculation gyre if the concurrent SSH value at the profiling location of the float exceeds $2.0 \mathrm{~m} .{ }^{1}$ As indicated by the white lines in Fig. 7, one clear difference between 2004 and 2005 is that the late winter mixed layer depth was much deeper in $2004\left(h_{m} \simeq 470 \mathrm{~m}\right)$ than in $2005\left(h_{m} \simeq 320 \mathrm{~m}\right)$. Here, the mixed layer depth is defined where $\sigma_{\theta}$ increases by $0.125 \mathrm{~kg} \mathrm{~m}^{-3}$ from its surface value [see Fig. $7 \mathrm{c}$ for the $\sigma_{\theta}(z, t)$ time series]. Because of the shallow winter mixed layer, winter convection was unable to penetrate through the entire lowPV STMW layer, and the PV value at the STMW's core

\footnotetext{
${ }^{1}$ Use of this threshold $\mathrm{SSH}$ value ensures that the $T-S$ profiles inside the KE jet and detached cold-core rings are excluded.
}

layer is found to be higher in 2005 than in 2004 (Fig. $7 d)$.

It is worth emphasizing that the difference in the late winter mixed layer depth is not due to weaker surface cooling in 2005. Figure 8 compares the net surface heat flux data averaged in the cooling seasons of October 2003-March 2004 versus October 2004-March 2005 based on the National Centers for Environmental Prediction-National Center for Atmospheric Research (NCEP-NCAR) reanalysis product (Kistler et al. 2001). Over the domain of our interest (the black dots in Fig. 8), the mean net surface heat flux values are comparable: $-275 \mathrm{~W} \mathrm{~m}^{-2}$ in 2004 versus $-283 \mathrm{~W} \mathrm{~m}^{-2}$ in 2005. Notice that the development of the convective winter mixed layer depends not only on the net heat flux forcing, but also on the stratification of the upper ocean. In the idealized case where the upper ocean has a constant buoyancy frequency $N$, for example, the convective mixed layer depth is determined by (Qiu and Chen 2006)

$$
h_{m}=\frac{1}{N}\left[\frac{-2 \alpha g}{\rho_{o} c_{p}} \int_{t} Q_{\mathrm{net}}\left(t^{\prime}\right) d t^{\prime}\right]^{1 / 2},
$$

where $\alpha$ is seawater's thermal expansion coefficient, $\rho_{o}$ is its reference density, $c_{p}$ is its heat capacity, and $Q_{\text {net }}$ is the net surface heat flux. Given the enhanced activity of cold-core rings in late 2004, the shallow winter mixed layer detected in March 2005 is likely due to the influence of the cold-core rings that brought the high PV, hence large $N$, northern KE water to the recirculation gyre (see discussions below). At present, a detailed upper-ocean budget analysis is being conducted using the KESS/KEO moored measurement data and the results will be reported in a forthcoming study (M. Cronin 2006, personal communication).

While no attempt is made to analyze the overall upper ocean heat budget in this study, the abundance of the profiling $T-S$ data around CCR-04B (Fig. 6) does provide us a good opportunity to quantify its effect on the STMW property changes. From the sequential SSH maps of Figs. 2 and 3, it is clear that in the period between its detachment from the trough of the KE's quasi-stationary meander in mid-December 2004 and its reabsorption by the KE jet in September 2005, CCR04B was the sole cold-core ring existing in the recirculation gyre region of $141^{\circ}-147^{\circ} \mathrm{E}$. During this 8 -month period, a significant increase in PV was observed in the STMW layer (recall Fig. 7d). Is a single eddy like CCR04B enough of a high-PV source to bring about the significant PV changes observed in the STMW layer?

To address this question, let us focus on the STMW core layer on the $25.375 \sigma_{\theta}$ surface. As shown in Fig. 7c, 

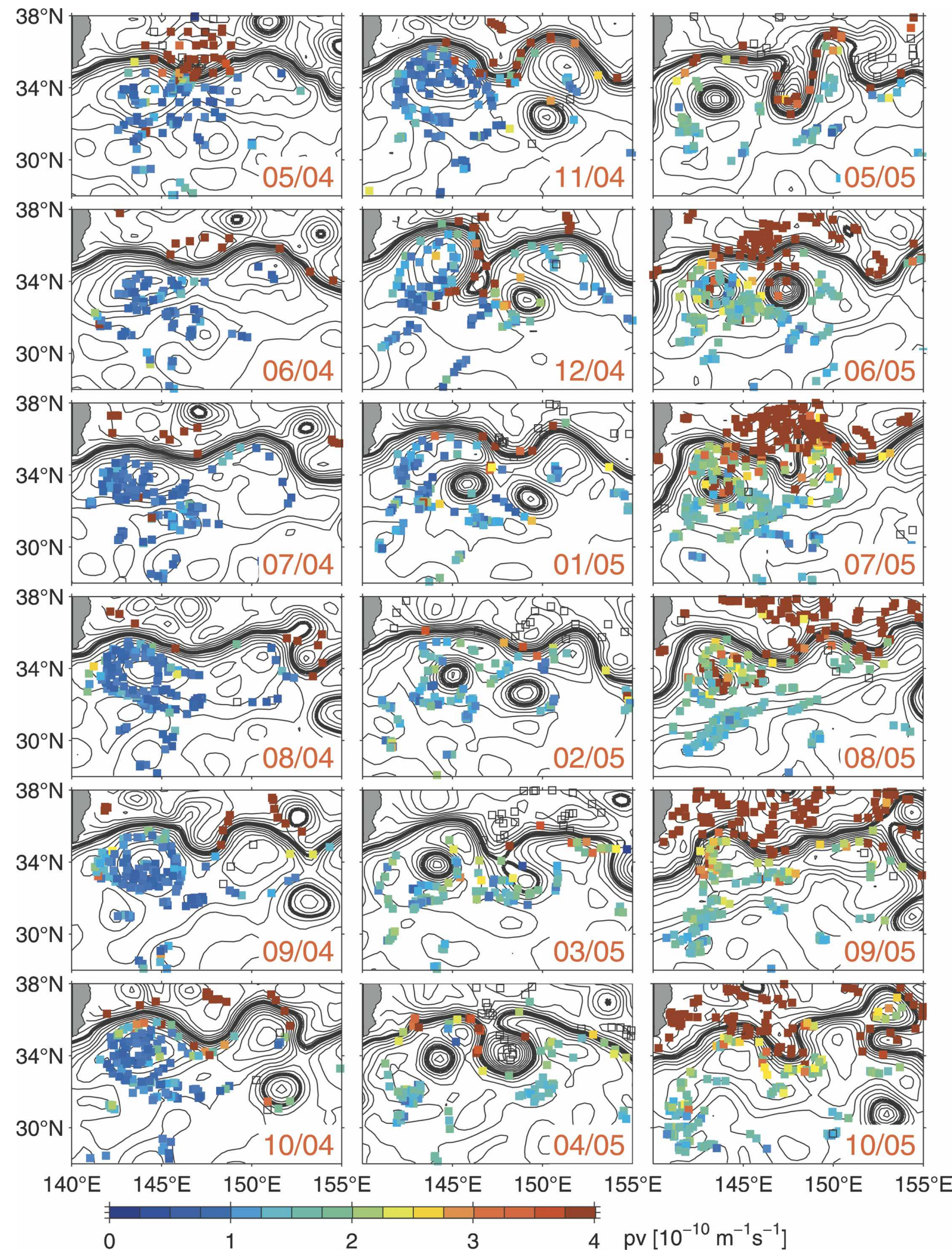

FIG. 6. Monthly distributions (from May 2004 to October 2005) of PV on the STMW core layer at the $25.375 \sigma_{\theta}$ surface. Colored squares indicate the PV values at the individual $T-S$ profile locations. Background contours indicate the monthly averaged SSH field. Contour intervals are $10 \mathrm{~cm}$, with the thick black lines denoting the 170 -cm contours. 


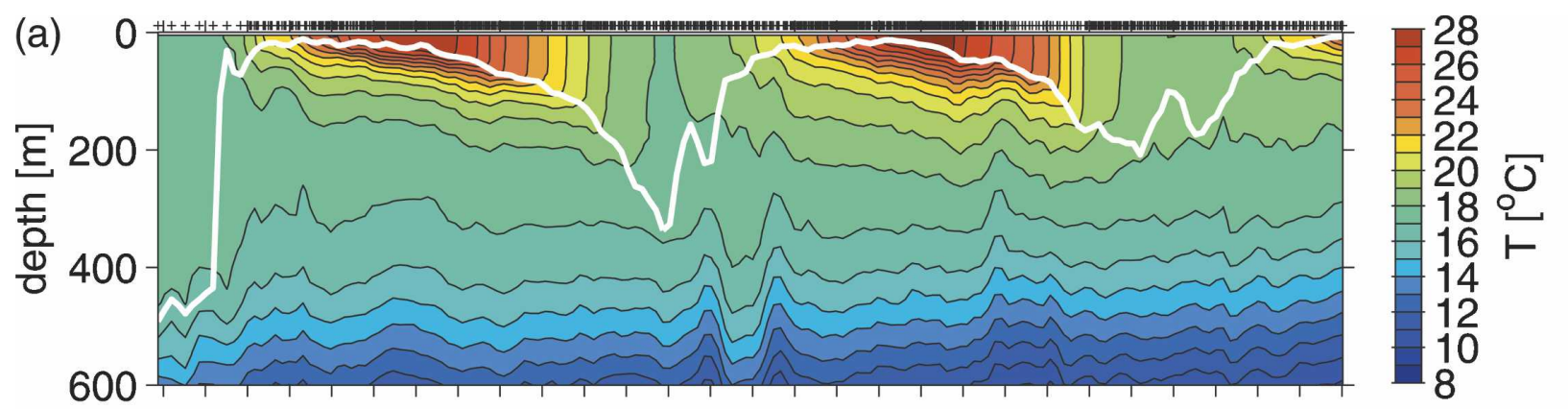

MAM J J A SOND J F MAM J JASOND J F M A J J

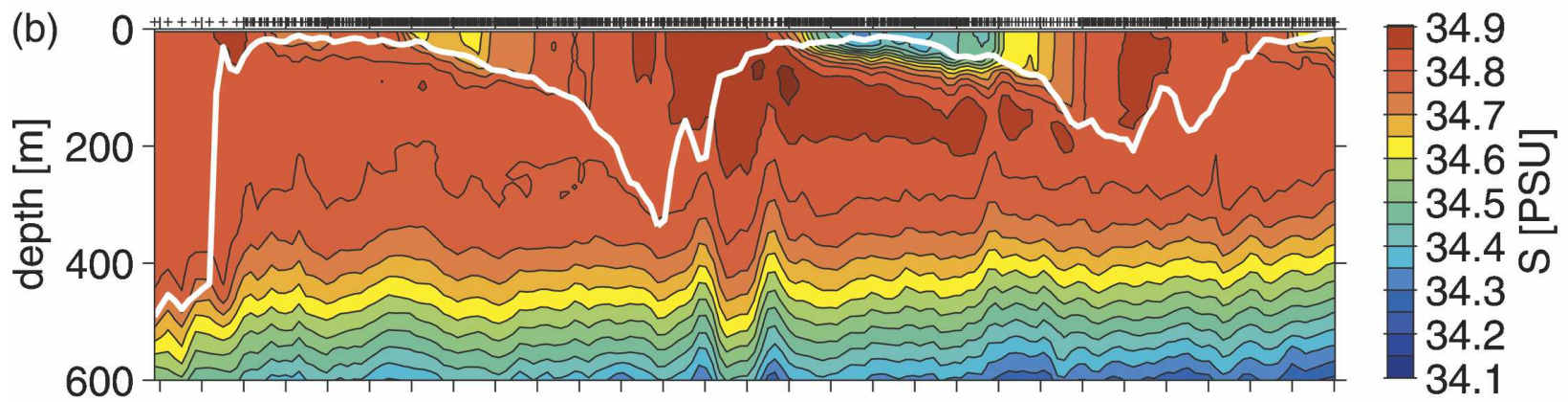

MAM J J A SOND J FMAM J JASOND J F MAM J J
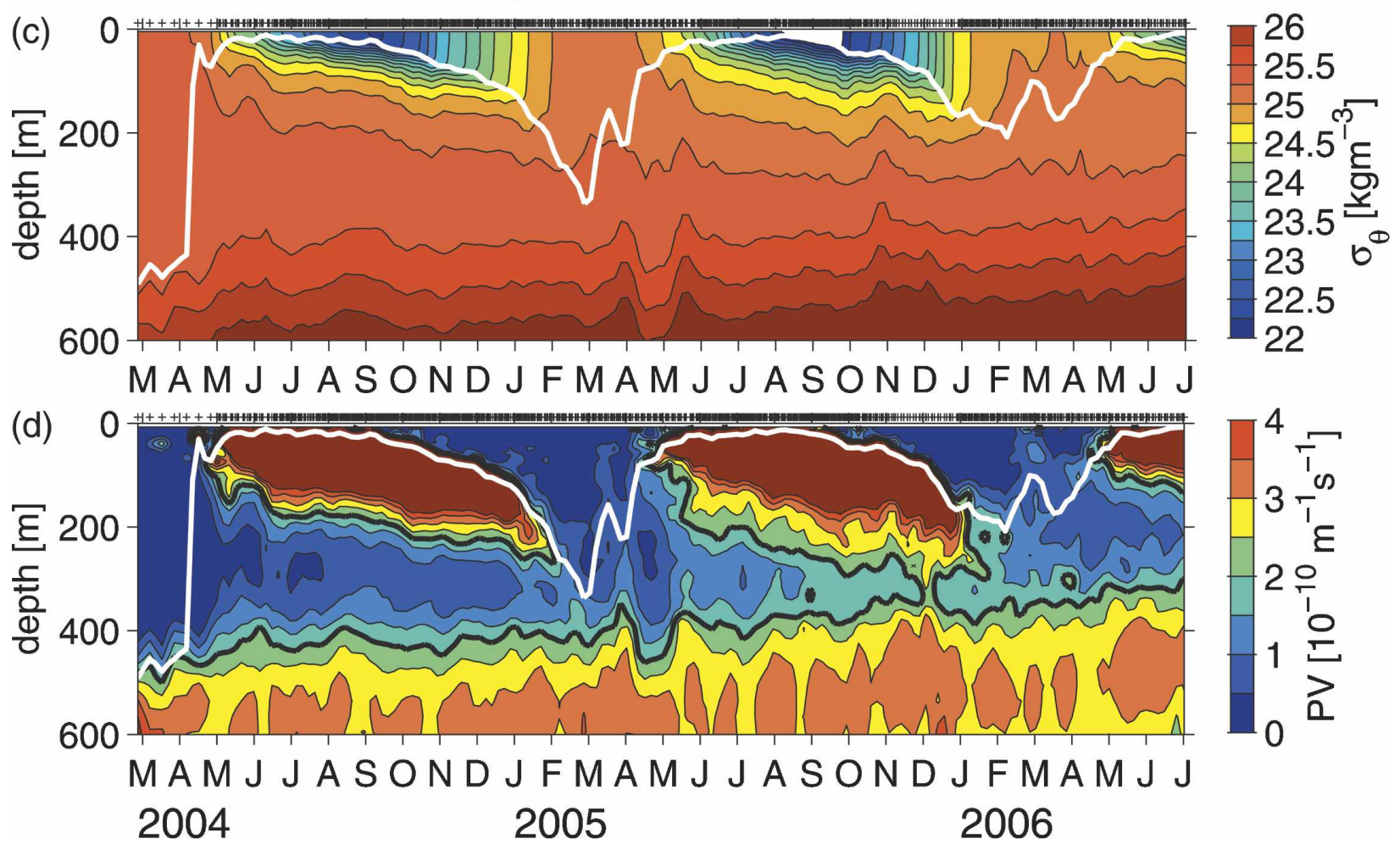

FIG. 7. Time series of (a) potential temperature, (b) salinity, (c) potential density, and (d) potential vorticity inside the recirculation gyre where SSH $>2.0 \mathrm{~m}$. Crosses at top of each panel indicate the available $T-S$ profiles. White contours denote the mixed later depth, defined as the depth at which $\sigma_{\theta}$ increases by $0.125 \mathrm{~kg} \mathrm{~m}^{-3}$ from its surface value. Thick black lines in (d) indicate the $Q=2 \times 10^{-10}$ $\mathrm{m}^{-1} \mathrm{~s}^{-1}$ contours. 

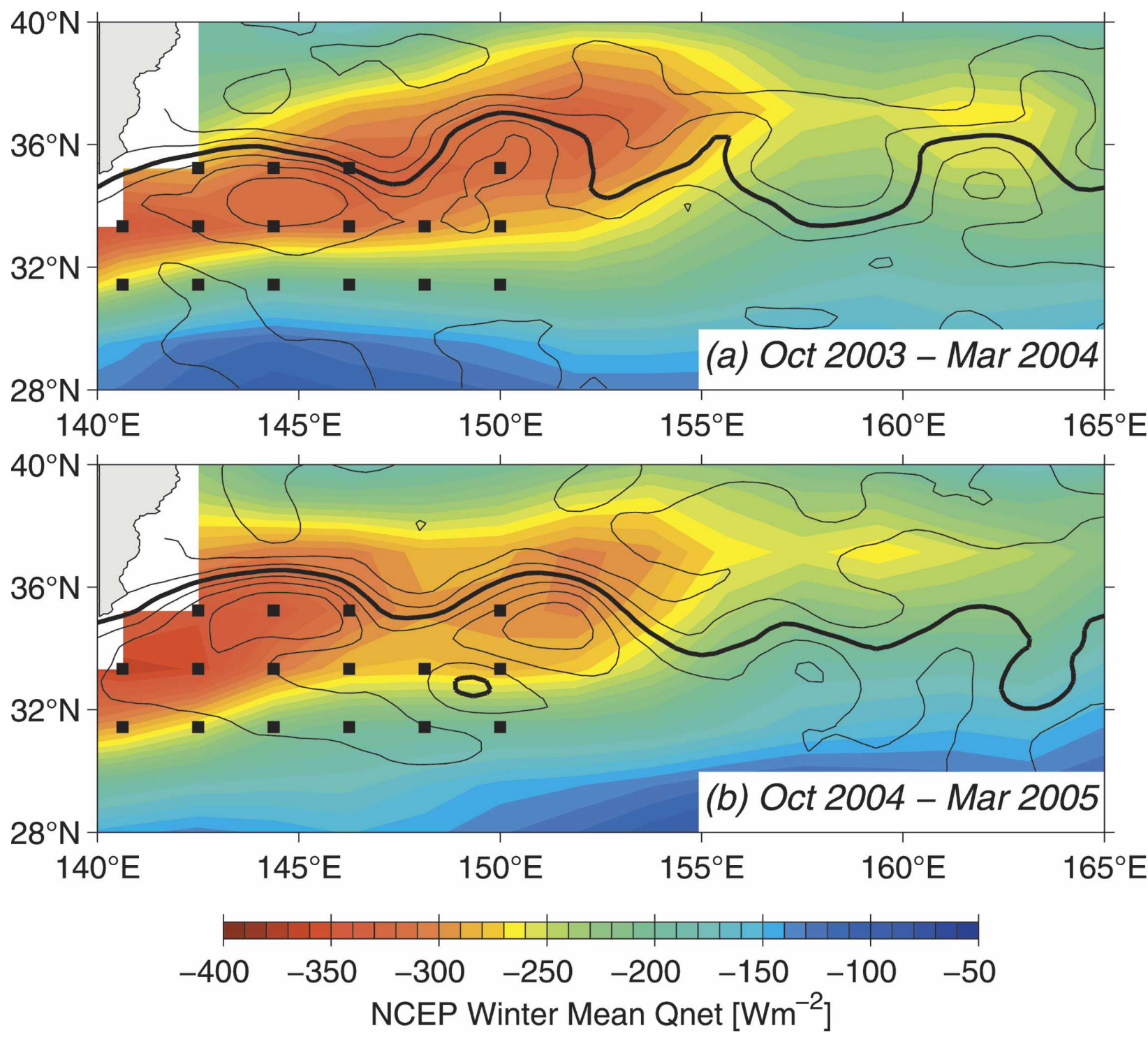

FIG. 8. Net surface heat flux maps (in color) averaged in the cooling seasons of (a) October 2003-March 2004 vs (b) October 2004-March 2005, based on the NCEP-NCAR reanalysis data. In the KE recirculation gyre of our interest (black dots), the areaaveraged heat flux values are $275 \mathrm{~W} \mathrm{~m}^{-2}$ in (a) and $283 \mathrm{~W} \mathrm{~m}^{-2}$ in (b), respectively. Background contours indicate the mean SSH during the period of consideration. Contour intervals are $20 \mathrm{~cm}$, with the thick black lines denoting the 170-cm contours.

while it was fully ventilated in late winter 2004, this isopycnal surface was barely touched by the deepened mixed layer in 2005. In other words, PV changes on this isopycnal surface after spring of 2004 can be expected to be influenced mostly by lateral processes, such as the eddy mixing due to CCR-04B. The fact that CCR-04B contained high-PV water of northern $\mathrm{KE}$ origin can be verified in Figs. 9 and 10. Figure 9 shows the PV value on the $25.375 \sigma_{\theta}$ surface as a function of SSH from the densely sampled CTD survey across the KE trough from the KESS cruise in May 2004 (see the inset for the CTD stations). Notice that the PV value on the north- ern edge of the KE jet on this isopycnal surface is nearly an order of magnitude higher than that in the recirculation gyre. This trough, as shown in Fig. 10, developed into CCR-04B in mid-December 2004 through its interaction with the impinging CCR-04A. It is clear from Fig. 10 that the core of CCR-04B contains the high-PV water originating in the northern edge of the KE jet.

Since we do not have enough float data to initialize the PV field for CCR-04B immediately after its detachment from the KE trough, this field is inferred indirectly as follows. From the SSH map of 15 December 


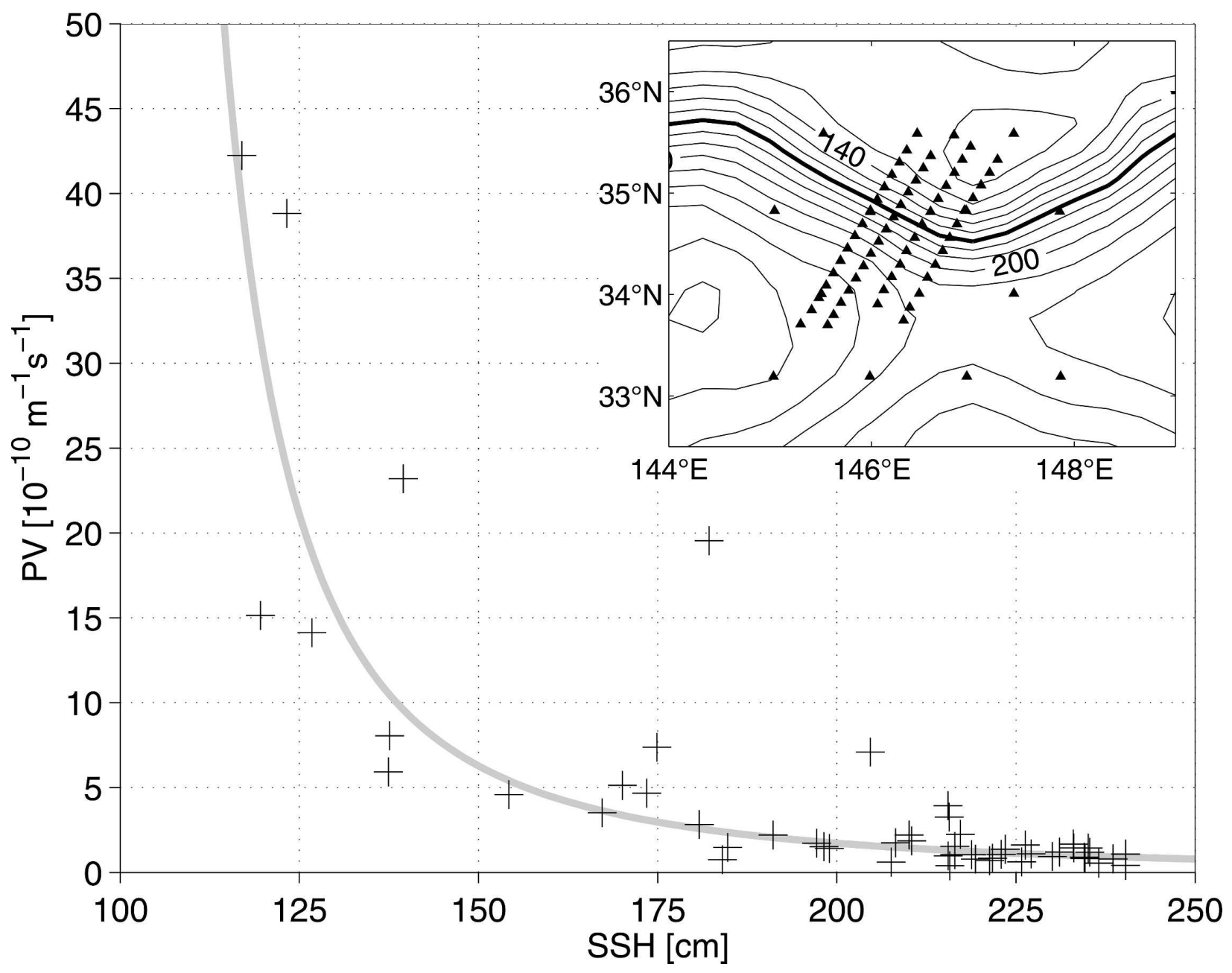

FIG. 9. Scatterplot (crosses) between the SSH and the PV value on the $25.375 \sigma_{\theta}$ surface in the KE meandering trough region in May 2004, based on the high-resolution CTD data obtained during the 2004 KESS cruise (see the inset for locations of the CTD stations). The gray curve denotes the least squares fit to $\mathrm{PV}=\alpha /(\mathrm{SSH}-95.0)^{2}$, where $\alpha$ is a constant.

2004 (Fig. 11a), we first evaluated the SSH value $h$ as a function of the radius $r$ from the center of CCR-04B. Once the profile $h(r)$ is established (see the Gaussian profile in Fig. 11b), we converted $h(r)$ to $Q(r)$ by using the $Q(h)$ relationship established by the high-resolution CTD survey conducted in May 2004 around the KE trough (Fig. 9). Square marks in Fig. 11c show the outcome of $Q(r)$ after converting all $h, Q$ pairs available in Fig. 9. Based on these marks, the PV distribution around CCR-04B on the $25.375 \sigma_{\theta}$ surface on 15 December $2004(t=0)$ is assumed to have the form

$$
Q(r, 0)=Q_{0}+Q_{1} \exp \left(-\frac{r^{2}}{a^{2}}\right),
$$

where $Q_{0}$ denotes the background PV value in the recirculation gyre unperturbed by CCR-04B; its value
$\left(Q_{0}=0.6 \times 10^{-10} \mathrm{~m}^{-1} \mathrm{~s}^{-1}\right)$ is determined from the available profiling float data prior to December 2004. From the least squares fit to the square marks in Fig. 11c, $Q_{1}$ and $a$ in Eq. (3) are chosen to be $40 \times 10^{-10}$ $\mathrm{m}^{-1} \mathrm{~s}^{-1}$ and $48 \mathrm{~km}$, respectively. The validity of this initial $Q(r, 0)$ pattern assumes that the $h-Q$ relationship observed in May 2004 around the KE trough is maintained through December 2004. Given the slow evolution of the KE trough during this period (see Fig. 2), we believe that this assumption is valid.

With the initial PV signal specified by Eq. (3), it is easy to show that if the high-PV anomalies of CCR-04B were to spread out evenly over the recirculation gyre region under consideration (i.e., a $4^{\circ}$ latitude $\times 6^{\circ}$ longitude box), the PV increase over the region would be:

$$
\Delta Q=\pi Q_{1} a^{2} / \text { Area }=1.2 \times 10^{-10} \mathrm{~m}^{-1} \mathrm{~s}^{-1} .
$$



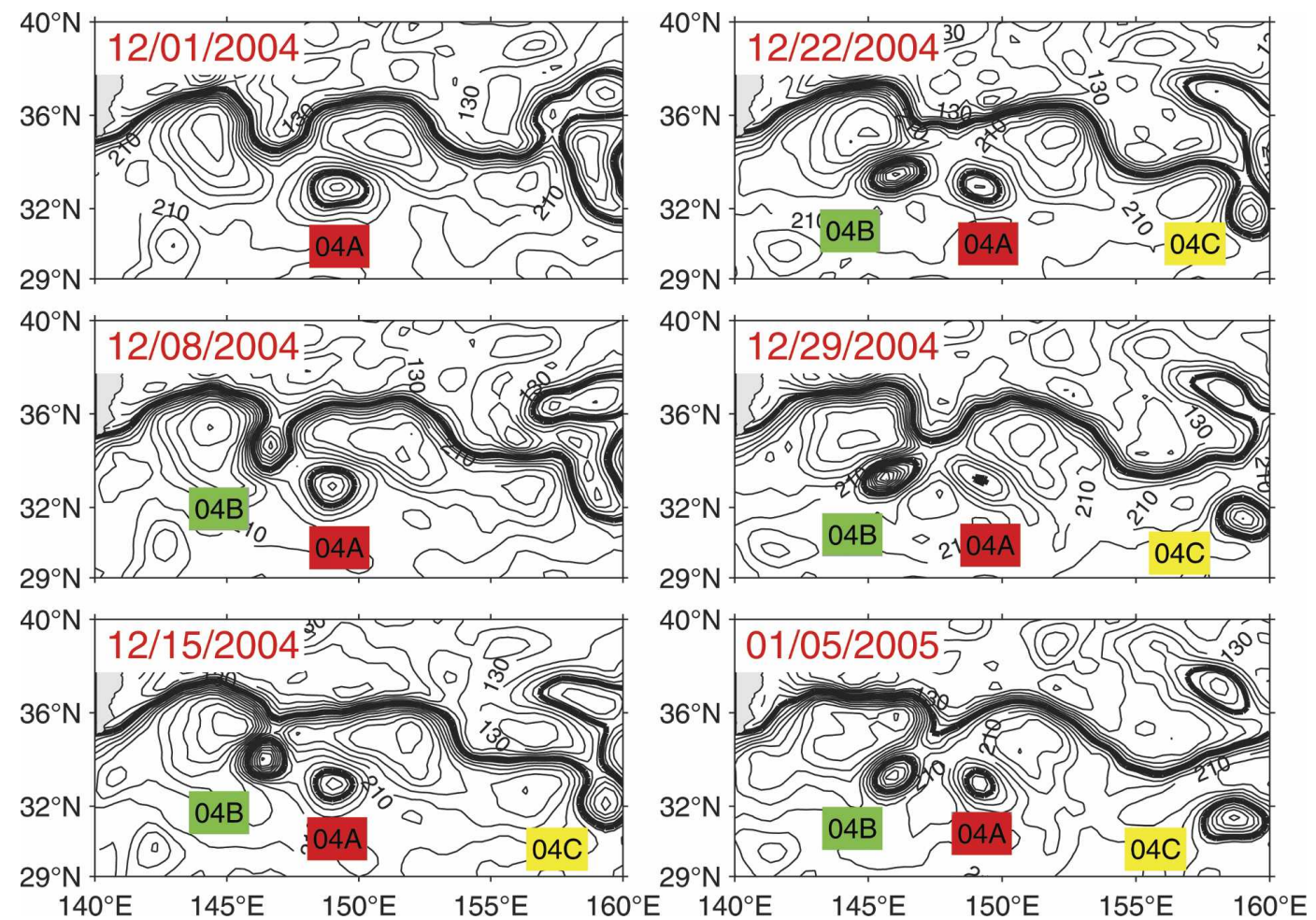

FIG. 10. Snapshots of the weekly SSH field in December 2004-January 2005. Contour intervals are $10 \mathrm{~cm}$, with the thick black lines denoting the 170-cm contours. The 1 Dec 2004 and 5 Jan 2005 snapshots are the same as those shown in Fig. 2.

In Fig. 7d, the observed PV change on the $25.375 \sigma_{\theta}$ surface from December 2004 to September 2005 is $1.0 \times 10^{-10} \mathrm{~m}^{-1} \mathrm{~s}^{-1}$, suggesting that CCR-04B alone would be sufficient to produce the PV change observed in the recirculation gyre. ${ }^{2}$

The fact that CCR-04B alone is capable of producing the observed PV changes in the recirculation gyre can also be appreciated from the strength of CCR-04B. As shown in Fig. 10, the observed SSH gradient across $\mathrm{CCR}-04 \mathrm{~B}, \sim 1.2 \mathrm{~m}$, is nearly as large as that across the $\mathrm{KE}$ jet. This implies that the upper-ocean transport associated with CCR-04B can reach a significant portion of the KE jet. Indeed, an evaluation based on the available profiling $T-S$ data around CCR-04B in JuneAugust, 2005, reveals that its volume transport in the surface $0-1500$-dbar layer reaches $62.2 \mathrm{~Sv}\left(1 \mathrm{~Sv} \equiv 10^{6}\right.$ $\mathrm{m}^{3} \mathrm{~s}^{-1}$; see appendix for the detailed transport estima-

\footnotetext{
${ }^{2}$ During the period from December 2004 to September 2005, CCR-04A hovered near $148^{\circ} \mathrm{E}$ and interacted vigorously with the KE jet (Figs. 2 and 3). The PV increase observed in Fig. 7d could, therefore, also be influenced by the high-PV source provided by CCR-04A. Lack of the $T-S$ measurements in the region downstream of $148^{\circ} \mathrm{E}$, however, prevented us from evaluating the CCR-04A's effects in detail.
}

tion). In light of the eddy dissipation with time, it is likely that CCR-04B could have a transport value larger than $62.2 \mathrm{~Sv}$ when it was initially detached from the KE jet in December 2004. In comparison, the volume transport of the KE jet in the surface 0-1500-dbar layer near the quasi-stationary trough in May 2004 was $104.7 \mathrm{~Sv}$ (see appendix). Clearly, CCR-04B constituted a significant portion of the KE jet (at least $60 \%$ of it) when it was injected into the recirculation gyre.

To evaluate the time-dependent influence of CCR04B after it moved into the recirculation gyre, we plot in Fig. 12 the time series of PV on the $25.375 \sigma_{\theta}$ surface within the concentric band $100-250 \mathrm{~km}$ out from the center of CCR-04B. As CCR-04B has an initial radius of $\sim 90 \mathrm{~km}$, this time series represents the PV evolution in the STMW core layer surrounding, but not within, CCR-04B. It is interesting to note that the increase in PV occurred mainly in the first five months following the CCR-04B's detachment in December 2004. The level of the PV increase was significant: from $0.80 \times$ $10^{-10} \mathrm{~m}^{-1} \mathrm{~s}^{-1}$ in December 2004 to $1.75 \times 10^{-10} \mathrm{~m}^{-1}$ $\mathrm{s}^{-1}$ in May 2005. After May 2005, the PV signal in the surroundings of CCR-04B remained largely constant.

The process through which the high-PV CCR-04B water is mixed into the surrounding STMW is likely due 

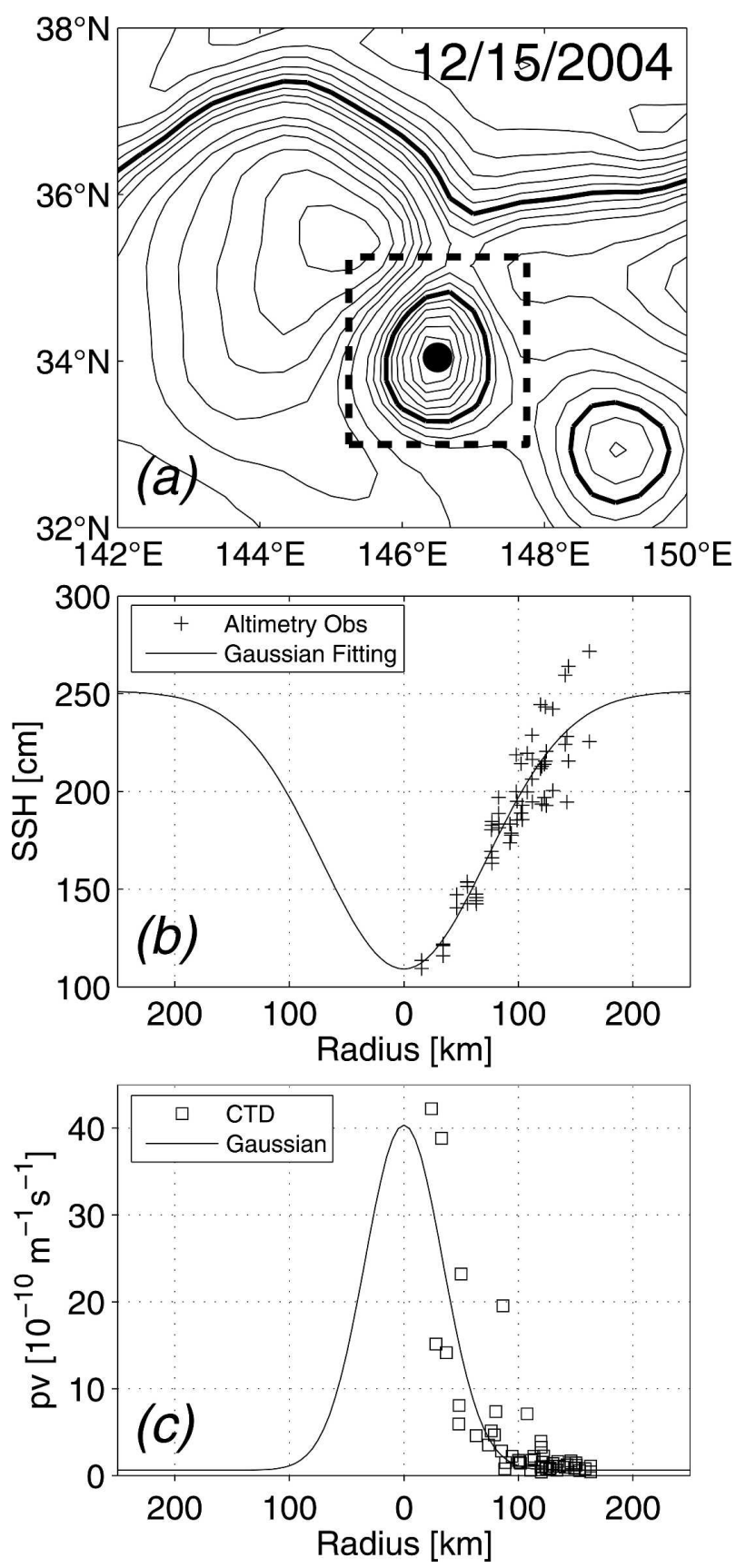

FIG. 11. (a) SSH field on 15 Dec 2004 following the detachment of CCR04B from the KE meandering trough (see Fig. 10 for the sequence of the SSH field). (b) SSH values surrounding CCR04B [inside the dashed box in (a)] plotted as a function of radial distance from the center of CCR-04B. The solid curve denotes the least squares fit to a Gaussian SSH profile, (c) PV values (squares) as a function of radial distance from the center of CCR-04B after utilizing the SSH-PV relationship plotted in Fig. 10. The solid curve denotes the least squares fit to a Gaussian function $Q_{0}+Q_{1}$ $\exp \left(-r^{2} / a^{2}\right)$.

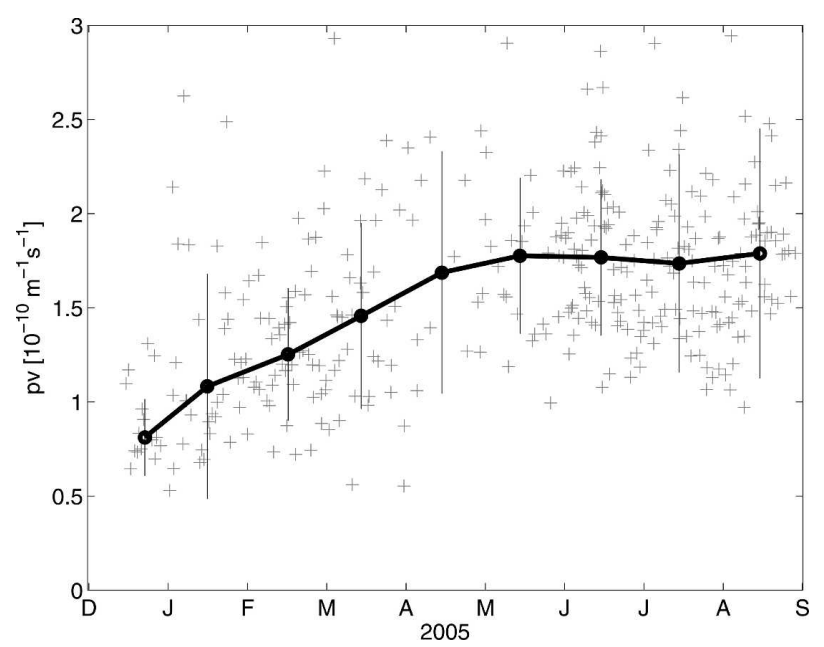

FIG. 12. Evolution of PV on the STMW core layer of $25.375 \sigma_{\theta}$ surface inside the recirculation gyre band $100-250 \mathrm{~km}$ out from the center of CCR-04B. Crosses indicate estimates from the individual profiles that fall within that band. The black circles denote the monthly averaged PV values and the vertical bars, the standard deviations.

to instabilities associated with the strong velocity shear between the cyclonic CCR-04B and the anticyclonic recirculation gyre. Although the profiling float data are inadequate to explore this physical process in detail, it is possible to estimate the effectiveness of CCR-04B's influence by adopting the following isopycnal diffusion equation for $\mathrm{PV}$ on the $25.375 \sigma_{\theta}$ surface:

$$
\frac{\partial Q(r, t)}{\partial t}=A_{h} \frac{1}{r} \frac{\partial}{\partial r}\left[r \frac{\partial Q(r, t)}{\partial r}\right],
$$

where $A_{h}$ denotes the isopycnal eddy diffusivity and $r$ the radial distance from the center of CCR-04B. Given the slow migration of CCR-04B inside the recirculation gyre (Figs. 2 and 3), we have ignored the advective effect of its movement in Eq. (4). Subject to the initial condition Eq. (3), Eq. (4) has the solution

$$
Q(r, t)=Q_{0}+\frac{a^{2} Q_{1}}{4 A_{h} t+a^{2}} \exp \left(-\frac{r^{2}}{4 A_{h} t+a^{2}}\right) .
$$

In Fig. 13, we plot the $Q(r, t)$ evolution averaged in the band of $r=100-250 \mathrm{~km}$ based on Eq. (5). Here, the value for eddy diffusivity has been selected parametrically. For comparison, the observed PV evolution averaged in the same $r=100-250-\mathrm{km}$ band is included in Fig. 13 as the black curve. The model result, especially that with $A_{h}=300 \mathrm{~m}^{2} \mathrm{~s}^{-1}$, is found to favorably reproduce the observed PV evolution surrounding CCR04B.

It is worth commenting that this $A_{h}=300 \mathrm{~m}^{2} \mathrm{~s}^{-1}$ value is smaller than the eddy diffusivity values inferred 


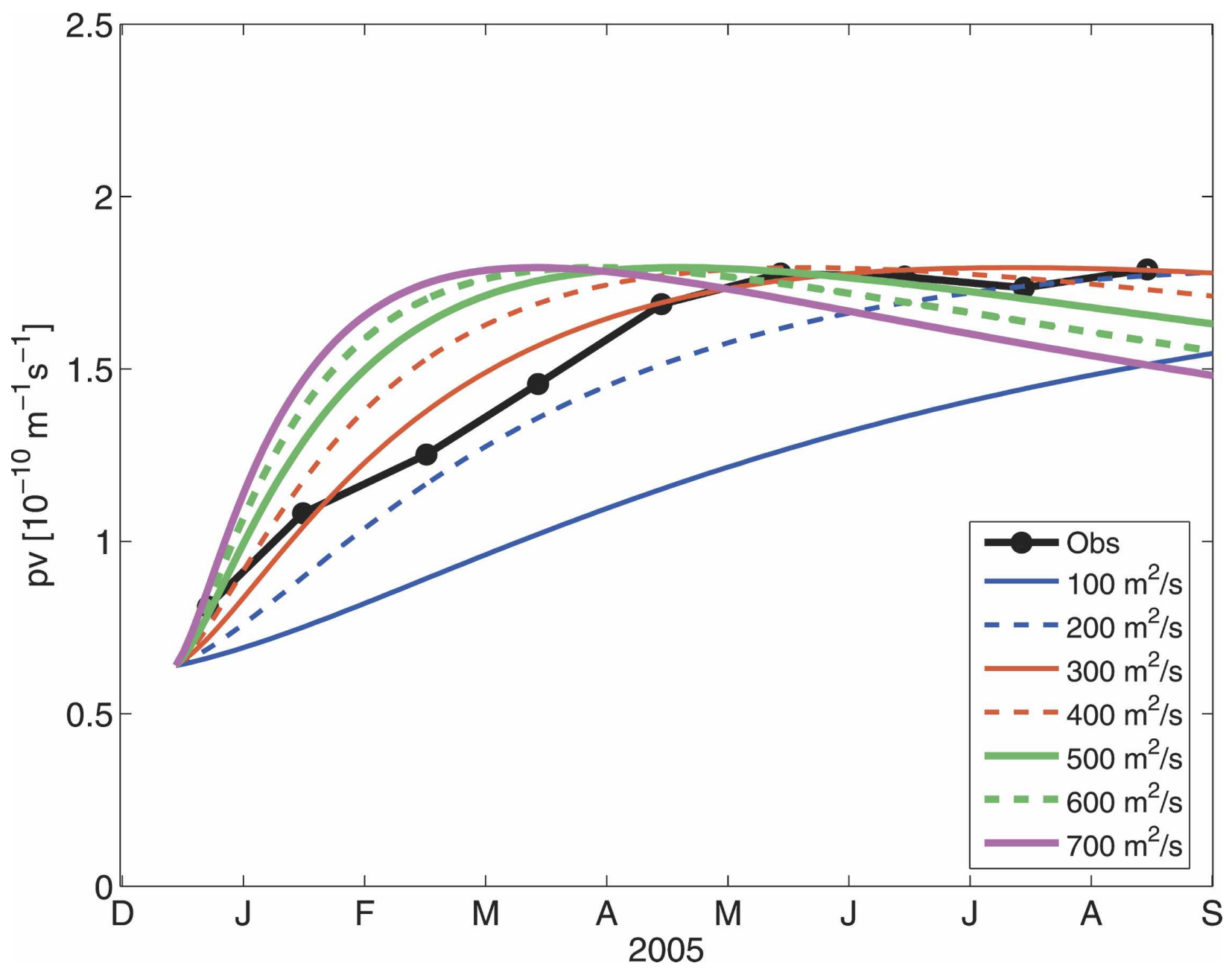

FIG. 13. Comparison between the observed and modeled evolutions of PV on the STMW core layer of $25.375 \sigma_{\theta}$ surface inside the recirculation gyre band 100-250 km out from the center of CCR-04B. The observed curve (black) is the one derived in Fig. 12. The model results are based on Eq. (5), where the value for eddy diffusivity is chosen parametrically and listed in the inset.

by Stammer (1998) using the mixing length hypothesis and satellite altimetric data, and by Ferreira et al. (2005) using a residual-mean ocean general circulation model and its adjoint. In the KE recirculation gyre region, their estimated $A_{h}$ values range typically from 1000 to $2000 \mathrm{~m}^{2} \mathrm{~s}^{-1}$. This difference is, however, understandable because the eddy mixing considered in the Stammer and Ferreira et al. studies is dominated by eddy generations along the unstable KE jet. As typified by the formation of CCR-04B (recall Fig. 10), the eddy shedding process is much more efficient in mixing different water masses than the lateral diffusion process following the eddy's cutoff. Eddy mixing, at the level of $A_{h}=300 \mathrm{~m}^{2} \mathrm{~s}^{-1}$, in the recirculation gyre is nevertheless significant: it was able to alter the PV signals of STMW by a factor of two on intra-annual time scales.

\section{Discussions and summary}

It has been known for three decades that the region surrounding the Kuroshio Extension in the western North Pacific has a high level of mesoscale eddy variability (e.g., Wyrtki et al. 1976). It is only in recent years, after the decade-long accumulation of the global satellite altimeter data, that it has become recognized that this mesoscale eddy variability modulates on a decadal time scale, and that the eddy field modulation is closely connected to the dynamic state of the KE system. The need to better understand the causes and effects of the mesoscale eddies has led to the initiation of the collaborative research program: the Kuroshio Extension System Study.

Beginning in January 2002, the KE system exhibited a stable state in which the KE path was relatively stable 
and the southern recirculation gyre was intense and well defined (Qiu and Chen 2005). This stable state of the KE, however, transitioned to a more temporally variable state in late 2004 while the KESS field program was underway. Underlying this recent transition is the shift of the PDO-related, basin-scale surface wind forcing that occurred in mid 2002. As the PDO changed from a negative phase to positive, the enhanced positive wind stress curl worked to lower the SSH in the central North Pacific Ocean. The arrival of these negative, wind-driven SSH anomalies from the east weakened the strength of the zonal jet and the KE's transition to an unstable state was preceded by an intense cold-core ring, CCR-04A, generated near the Shatsky Rise in May 2004.

As CCR-04A migrated westward, it interacted vigorously with the KE jet and caused the detachment of CCR-04B from the KE meandering trough around $146^{\circ} \mathrm{E}$ in December 2004. Following CCR-04A, two additional cold-core rings, CCR-04C and CCR-05A, were generated near the Shatsky Rise in late 2004 and mid 2005 , respectively. Through both their direct presence and their interactions with the KE jet, these four coldcore eddies further weakened the strength of the southern recirculation gyre (in addition to the weakening caused by the incoming, wind-driven negative SSH anomalies) and elevated significantly the eddy kinetic energy level in the upstream KE region in 2005.

By analyzing the profiling T-S data from the KESS and Argo projects, we found that the enhanced mesoscale eddy activity in 2005 exerted a relatively fast and measurable impact upon the water mass properties in the recirculation gyre. As compared with $Q \simeq 0.5 \times$ $10^{-10} \mathrm{~m}^{-1} \mathrm{~s}^{-1}$ in 2004 , the potential vorticity value at the STMW core layer increased to above $1.0 \times 10^{-10}$ $\mathrm{m}^{-1} \mathrm{~s}^{-1}$ in 2005. With the aid of an eddy diffusion model, we found that this weakening in the low-PV signal of STMW was due to the cold-core eddies that transport and infuse the high-PV water of the northern $\mathrm{KE}$ origin into the recirculation gyre. The effective eddy diffusivity for PV in the STMW core layer is estimated to be on the order of $300 \mathrm{~m}^{2} \mathrm{~s}^{-1}$.

Both the data analysis and the modeling result in this study show that the impact on the STMW signal by the cold-core eddies occurs on a time scale of a few months. This result is important because it indicates that the STMW properties respond effectively to the changes in the dynamic state of the KE system. Indeed, if the eddy erosion were a slow process that occurs on interannual or longer time scales, one would expect the STMW signals to reflect more the year-to-year changes in the wintertime atmospheric conditions. The fact that the eddy erosion occurs on the intra-annual time scale supports our recent findings based on historical temperature data that the changes in the STMW formation in the last decade depended more sensitively on the dynamic state of the KE than on the overlying atmospheric conditions (Qiu and Chen 2006).

It is worth noting that like the KE, the Gulf Stream (GS) system in the North Atlantic also undergoes transitions between an elongated and a contracted state (Kelly and Dong 2004). Opposite to our findings for the KE system, Dong et al. (2007) show that more (less) $18^{\circ}$ water is formed when the GS recirculation gyre weakens (strengthens). Two factors appear to contribute to the difference between these two western boundary current extension systems. First, Dong et al. (2007) find no appreciable changes in the main thermocline depth of the GS recirculation gyre between the two dynamic states. This is very different from the thermocline depth changes observed in the KE recirculation gyre. As represented by the $14^{\circ} \mathrm{C}$ isotherm in Fig. $7 \mathrm{a}$, the thermocline depth in the KE recirculation gyre shoaled by $\sim 70 \mathrm{~m}$ after the KE system transitioned from a stable state in 2004 to an unstable state in 2005. This shoaling is due both to the wind-induced, negative SSH signals propagating from the central North Pacific, and to the cutoff cold-core eddies that diffuse in the recirculation gyre. Second, Dong et al. (2007) find that the wintertime, upper-ocean temperatures in the GS recirculation gyre can differ by more than $2^{\circ} \mathrm{C}$ between the two dynamic states (the elongated state has a warmer upper-ocean temperature, see their Fig. 2). In the KE recirculation gyre, the wintertime upper ocean temperatures remain largely constant, irrespective of the KE's dynamic state. The lack of temperature change can be seen in Fig. 14, which compares the sea surface temperature (SST) distribution in March 2004 with that in March 2005. Despite the very different dynamic state of the KE during these $2 \mathrm{yr}$, the SST over the broad recirculation gyre region remained in the same $17^{\circ}-18^{\circ} \mathrm{C}$ range. The result of Fig. 14 is consistent with the independent profiling float data presented in Fig. 7a: in the months when the winter mixed layer was deepest, the upper ocean temperature in the $\mathrm{KE}$ recirculation gyre was $17^{\circ}-18^{\circ} \mathrm{C}$ in both 2004 and 2005.

The STMW formation, as we noted in Eq. (2), is sensitive to the stratification of the upper ocean. When the $\mathrm{KE}$ is in a stable state, the thicker thermocline layer tends to weaken the upper ocean stratification, thereby favoring the STMW formation. When the GS is in a stable state, on the other hand, the upper-ocean temperature increases whereas the thermocline thickness 


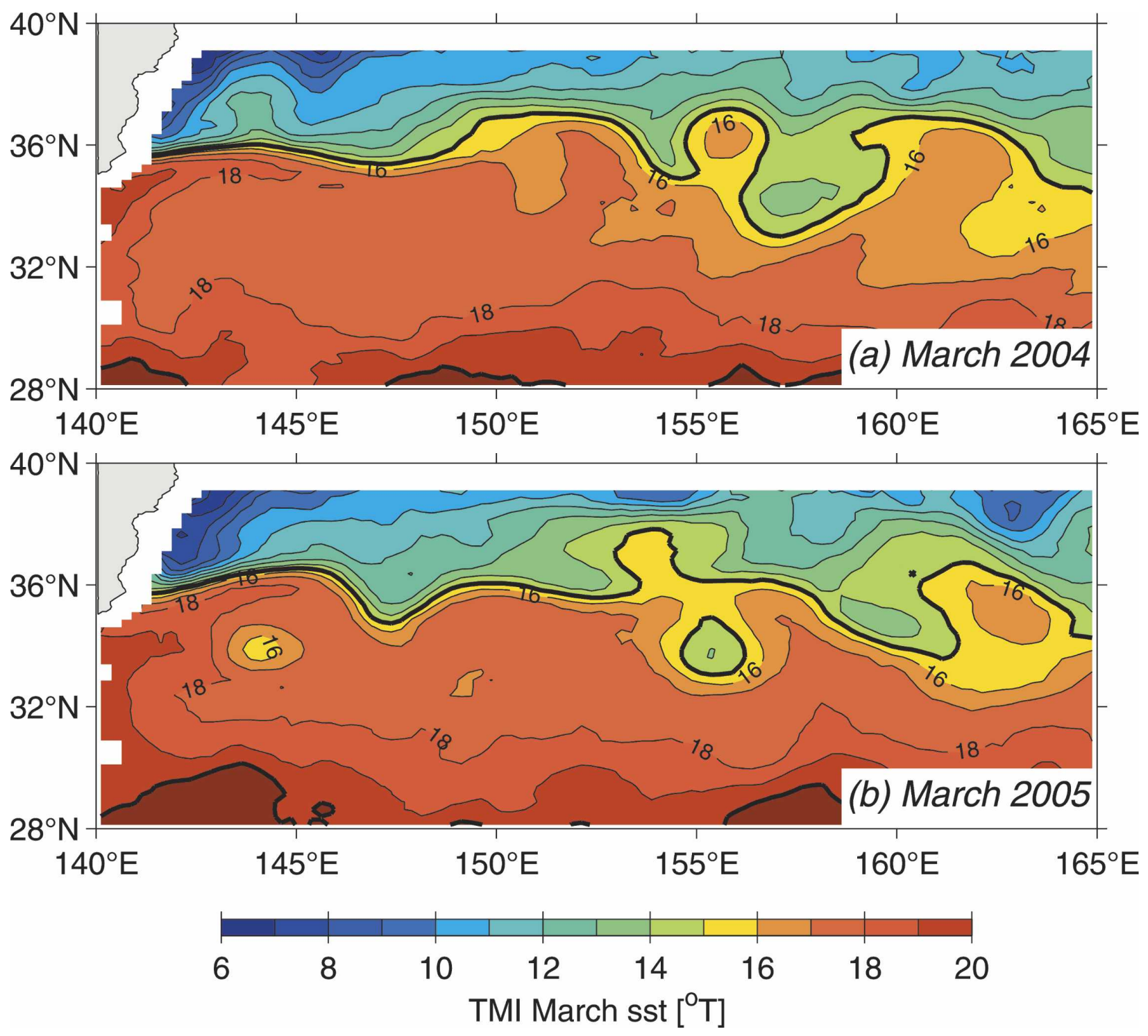

FIG. 14. Sea surface temperature distributions in the KE region: (a) March 2004 and (b) March 2005. Contour intervals are $1{ }^{\circ} \mathrm{C}$. Based on the TRMM Microwave Imager (TMI) data.

remains constant. These conditions tend to increase the stratification and thus do not favor STMW formation.

For the KE recirculation gyre, we have investigated the dynamics governing the changes in the $\mathrm{SSH}$, or equivalently the main thermocline depth, between the two dynamic states. It remains to be explored what determines the relatively stable, late winter upperocean temperatures in the different dynamic states of the KE system.

Acknowledgments. This study benefited from the collaborations with the other KESS principal investigators: Meghan Cronin, Kathy Donohue, Nelson Hogg, Steve Jayne, Humio Mitsudera, Randy Watts, and
Shang-Ping Xie. Detailed comments made by Ted Durland, Kathie Kelly, Toshio Suga, and an anonymous reviewer helped to improve an early version of the manuscript. The Argo profiling float data used in this study were provided by the US-GODAE Argo Global Data Assembly Center, the surface wind stress and heat flux data are from the National Centers for Environmental Prediction, the TMI data were provided by Remote Sensing Systems, and the merged T/P, Jason-1, and ERS-1/2 altimeter data are from the CLS Space Oceanography Division as part of the Environment and Climate EU ENACT project. This study was supported by NSF through Grant OCE-0220680 and NASA through Contract 1207881. 

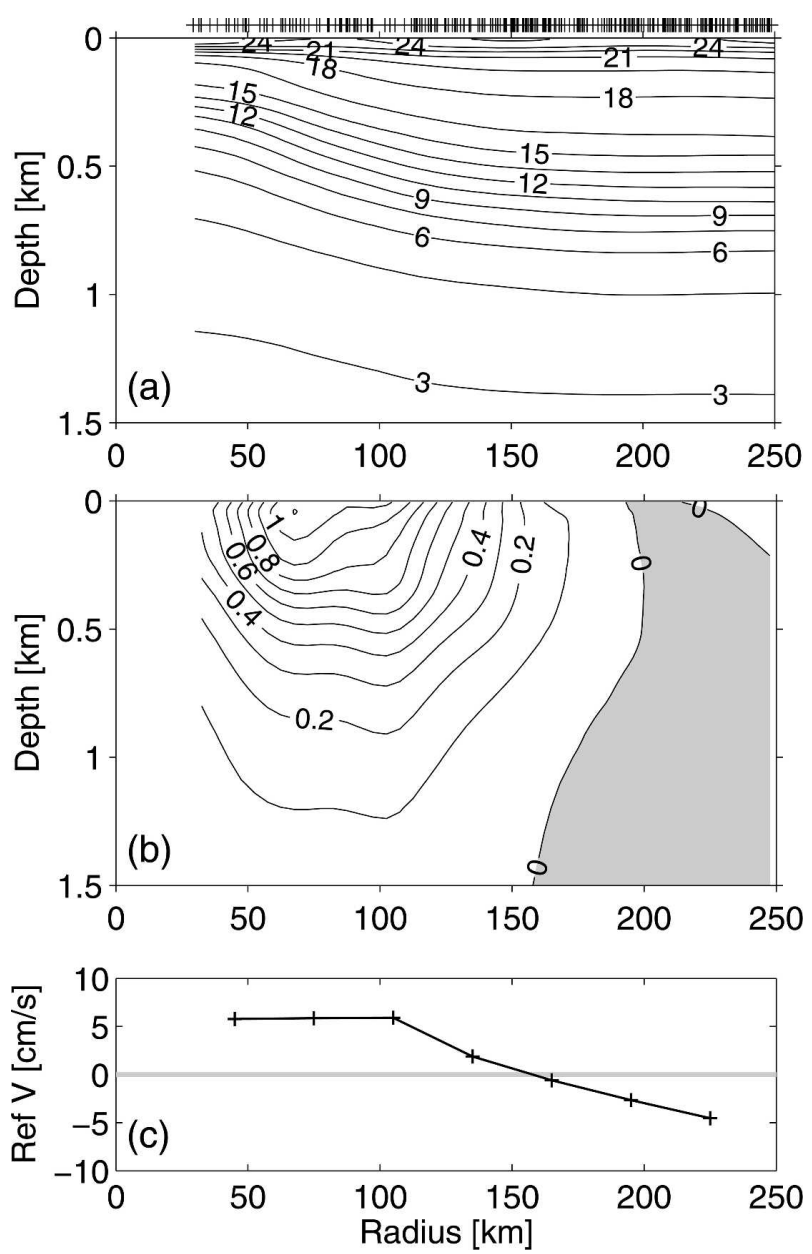

FIG. A1. (a) Temperature section $\left({ }^{\circ} \mathrm{C}\right)$ across CCR-04B in June-August 2005. Crosses indicate the individual profiles that are used in constructing the section. (b) Azimuthal velocity $\left(\mathrm{m} \mathrm{s}^{-1}\right.$ ) around CCR-04B calculated geostrophically from the $T-S$ sections plus the reference velocity shown in (c). (c) Azimuthal velocity at the reference level of $1500 \mathrm{dbar}$, calculated from the drifting velocities of the profiling floats at their parking depth.

\section{APPENDIX}

\section{Transport Estimations for CCR-04B and the KE Jet}

To evaluate the volume transport of CCR-04B, we collected all $T-S$ profiles around the ring from June to August 2005 (see Fig. 6 for the available data points). Figure A1a shows the temperature section as a function of the radial distance from the center of CCR-04B after averaging the available temperature measurements. A section for salinity is similarly obtained (not shown). From the $T-S$ sections, we calculate the azimuthal geostrophic velocity relative to the 1500 -dbar level. To estimate the velocity at this reference level, we utilize the drifting information from the profiling floats (all KESS floats have a parking depth at 1500 dbar). Figure A1c shows the azimuthal velocity after averaging all available drifting velocities. With this estimated reference velocity, Fig. A1b shows the total azimuthal flow field associated with CCR-04B. Integrating the positive flows in Fig. A1b reveals that CCR-04B has a volume transport of $62.2 \mathrm{~Sv}$ in the surface 0-1500-dbar layer.

To determine the volume transport for the KE jet, we use the high-resolution CTD data taken across the KE jet near $146^{\circ} \mathrm{E}$ from the May $2004 \mathrm{KESS}$ cruise (see the inset in Fig. 9). The $T-S$ sections from the cruise are presented in Fig. 4 of Qiu et al. (2006). As the concurrent ship-board ADCP measurements were available during the CTD surveys (see Fig. 5 of Qiu et al. 2006), they are used to determine the unknown reference velocities. The total volume transport of the KE jet in the surface $0-1500$-dbar layer is estimated at $104.7 \mathrm{~Sv}$.

\section{REFERENCES}

Bingham, F. M., 1992: Formation and spreading of Subtropical Mode Water in the North Pacific. J. Geophys. Res., 97, 11 177-11 189.

_ T. Suga, and K. Hanawa, 1992: Comparison of upper ocean thermal conditions in the western North Pacific between two pentads: 1938-42 and 1978-82. J. Oceanogr., 48, 405-425.

Conkright, M. E., R. A. Locarnini, H. E. Garcia, T. D. O'Brien, T. P. Boyer, C. Stephens, and J. I. Antonov, 2002: World Ocean Atlas 2001: Objective analyses, data statistics, and figures. CD-ROM documentation. National Oceanographic Data Center, $17 \mathrm{pp}$.

Deser, C., M. A. Alexander, and M. S. Timlin, 2003: Understanding the persistence of sea surface temperature anomalies in midlatitude. J. Climate, 16, 57-72.

Dong, S., S. L. Hautala, and K. A. Kelly, 2007: Interannual variations in upper ocean heat content and heat transport convergence in the western North Atlantic. J. Phys. Oceanogr., in press.

Ducet, N., P.-Y. Le Traon, and G. Reverdin, 2000: Global highresolution mapping of ocean circulation from TOPEX/ Poseidon and ERS-1 and -2. J. Geophys. Res., 105, $19477-$ 19498.

Ebuchi, N., and K. Hanawa, 2001: Trajectory of mesoscale eddies in the Kuroshio recirculation region. J. Oceanogr., 57, 471480.

Ferreira, D., J. Marshall, and P. Heimbach, 2005: Estimating eddy stresses by fitting dynamics to observations using a residualmean ocean circulation model and its adjoint. J. Phys. Oceanogr., 35, 1891-1910.

Hanawa, K., and J. Kamada, 2001: Variability of core layer temperature (CLT) of the North Pacific subtropical mode water. Geophys. Res. Lett., 28, 2229-2232.

—, and L. D. Talley, 2001: Mode waters. Ocean Circulation and Climate: Observing and Modelling the Global Ocean, G. Siedler, J. Church, and J. Gould, Eds., Academic Press, 373386.

Hurlburt, H. E., A. J. Wallcraft, W. J. Schmitz, P. J. Hogan, and E. J. Metzger, 1996: Dynamics of the Kuroshio/Oyashio current system using eddy-resolving models of the North Pacific Ocean. J. Geophys. Res., 101, 941-976.

Kelly, K. A., 2004: The relationship between oceanic heat trans- 
port and surface fluxes in the western North Pacific: 19702000. J. Climate, 17, 573-588.

_ - and S. Dong, 2004: The relationship of western boundary current heat transport and storage to mid-latitude oceanatmosphere interaction. Earth's Climate: The OceanAtmosphere Interaction, Geophys. Monogr., Vol. 147, Amer. Geophys. Union, 347-363.

Kistler, R., and Coauthors, 2001: The NCEP-NCAR 50-Year Reanalysis: Monthly means CD-ROM and documentation. Bull. Amer. Meteor. Soc., 82, 247-267.

Le Traon, P.-Y., and G. Dibarboure, 1999: Mesoscale mapping capabilities of multiple-satellite altimeter missions. J. Atmos. Oceanic Technol., 16, 1208-1223.

Mantua, N. J., S. R. Hare, Y. Zhang, J. M. Wallace, and R. C. Francis, 1997: A Pacific interdecadal climate oscillation with impacts on salmon production. Bull. Amer. Meteor. Soc., 78, 1069-1079.

Masuzawa, J., 1969: Subtropical mode water. Deep-Sea Res., 16, $463-472$.

— 1972: Water characteristics of the North Pacific central region. Kuroshio-Its Physical Aspects, H. Stommel and K. Yoshida, Eds., University of Tokyo Press, 95-127.

Mizuno, K., and W. B. White, 1983: Annual and interannual variability in the Kuroshio Current system. J. Phys. Oceanogr., 13, 1847-1867.

Oka, E., and T. Suga, 2003: Formation region of North Pacific subtropical mode water in the late winter of 2003. Geophys. Res. Lett., 30, 2205, doi:10.1029/2003GL018581.

Qiu, B., 2002: The Kuroshio Extension system: Its large-scale variability and role in the midlatitude ocean-atmosphere interaction. J. Oceanogr., 58, 57-75.

_ 2003: Kuroshio Extension variability and forcing of the Pacific decadal oscillations: Responses and potential feedback. J. Phys. Oceanogr., 33, 2465-2482.

— recirculation gyre and mesoscale eddies on decadal timescales. J. Phys. Oceanogr., 35, 2090-2103.

, and — 2006: Decadal variability in the formation of the North Pacific Subtropical Mode Water: Oceanic versus atmospheric control. J. Phys. Oceanogr., 36, 1365-1380.
—, P. Hacker, S. Chen, K. A. Donohue, D. R. Watts, H. Mitsudera, N. G. Hogg, and S. R. Jayne, 2006: Observations of the Subtropical Mode Water evolution from the Kuroshio Extension System Study. J. Phys. Oceanogr., 36, 457-473.

Stammer, D., 1998: On eddy characteristics, eddy transports, and mean flow properties. J. Phys. Oceanogr., 28, 727-739.

Suga, T., and K. Hanawa, 1995a: The Subtropical Mode Water circulation in the North Pacific. J. Phys. Oceanogr., 25, 958970.

$\longrightarrow$, and — 1995b: Interannual variations of North Pacific Subtropical Mode Water in the $137^{\circ} \mathrm{E}$ section. J. Phys. Oceanogr., 25, 1012-1017.

—, K. Motoki, Y. Aoki, and A. M. MacDonald, 2004: The North Pacific climatology of winter mixed layer and mode waters. J. Phys. Oceanogr., 34, 3-22.

Talley, L. D., 1988: Potential vorticity distribution in the North Pacific. J. Phys. Oceanogr., 18, 89-106.

Taneda, T., T. Suga, and K. Hanawa, 2000: Subtropical mode water variation in the southwestern part of the North Pacific subtropical gyre. J. Geophys. Res., 105, 19 591-19 598.

Teague, W. J., M. J. Carron, and P. J. Hogan, 1990: A comparison between the Generalized Digital Environmental Model and Levitus climatologies. J. Geophys. Res., 95, 7167-7183.

Uehara, H., T. Suga, K. Hanawa, and N. Shikama, 2003: A role of eddies in formation and transport of North Pacific Subtropical Mode Water. Geophys. Res. Lett., 30, 1705, doi:10.1029/ 2003 GL017542.

Vivier, F., K. A. Kelly, and L. Thompson, 2002: Heat budget in the Kuroshio Extension region: 1993-1999. J. Phys. Oceanogr., 32, 3436-3454.

Wong, A., G. C. Johnson, and W. B. Owens, 2003: Delayed-mode calibration of autonomous CTD profiling float salinity data by $\theta-S$ climatology. J. Atmos. Oceanic Technol., 20, 308-318.

Wyrtki, K., L. Maygaad, and J. Hager, 1976: Eddy energy in the oceans. J. Geophys. Res., 81, 2641-2646.

Yasuda, T., and K. Hanawa, 1999: Composite analysis of North Pacific subtropical mode water properties with respect to the strength of the wintertime East Asian monsoon. J. Oceanogr., 55, 531-541. 